\title{
Vacunación neumocócica conjugada en adultos. Recomendaciones de las Sociedades Médicas en México
}

\author{
Mejía-Ávila ME, ${ }^{1} \bowtie$ Ávila-Fematt FMG, ${ }^{2}$ Aguilar-Navarro SG, ${ }^{3}$ Alatorre-Alexander JA, ${ }^{4}$ \\ Alcocer-Díaz Barreiro LA,${ }^{5}$ Báez-Saldaña R, ${ }^{6}$ Buendía-Roldán I, ${ }^{7}$ Carrillo-González PA, ${ }^{8}$ \\ Cornejo-Juárez P, ${ }^{9}$ Dávila-Valero JC, ${ }^{10}$ Donis-Hernández JJ, ${ }^{11}$ Franco-Cendejas R, ${ }^{12}$ \\ García-Figueroa JL, ${ }^{13}$ Guerrero-Almeida $M C,{ }^{14}$ Gutiérrez-Ureña SR,,${ }^{15}$ Hernández-Núñez E, ${ }^{16}$ \\ López-Enríquez CC, ${ }^{17}$ Pavia-Ruz N, ${ }^{18}$ Pedraza-Chávez J, ${ }^{19}$ Quintero-Beuló G, ${ }^{20}$ \\ Regalado-Pineda J, ${ }^{21}$ Rodríguez-García JA, ${ }^{22}$ Salazar-Lezama MA,${ }^{23}$ Sánchez-Mijangos JH, ${ }^{24}$ \\ Sánchez-Ríos CP, ${ }^{25}$ Solache-Ortiz G, ${ }^{26}$ Torres-Gutiérrez JL, ${ }^{27}$ Vázquez-Cortés JJ, ${ }^{28}$ \\ Vilar-Compte D, ${ }^{29}$ Wong-Chew RM, ${ }^{30}$ Zúñiga-Gil $\mathrm{CH}^{31}$
}

\footnotetext{
Presidente de la Sociedad Mexicana de Neumología y Cirugía de Tórax (SMNyCT), Ciudad de México;

2 Jefe de Enseñanza Médica del Hospital Regional «Lic. Adolfo López Mateos» ISSSTE, Ciudad de México;

${ }^{3}$ Investigador en Ciencias Médicas C/Profesor Titular de Posgrado de Geriatría, Instituto Nacional de Ciencias Médicas y Nutrición «Salvador Zubirán» (INCMNSZ), Ciudad de México;

${ }^{4}$ Jefe del Departamento de Oncología Torácica del Instituto Nacional de Enfermedades Respiratorias (INER), Ciudad de México;

${ }^{5}$ Director General del Instituto Mexicano de Salud Cardiovascular, Ciudad de México;

${ }^{6}$ Instituto Nacional de Enfermedades Respiratorias, Ciudad de México;

7 Jefe del Laboratorio de Investigación Traslacional en Envejecimiento y Enfermedades Fibrosantes, INER, Ciudad de México;

${ }^{8}$ Médico adscrito al Servicio de Endocrinología del Hospital Regional «Lic. Adolfo López Mateos» ISSSTE, Ciudad de México;

9 Jefe del Departamento de Infectología del Instituto Nacional de Cancerología (INCan), Ciudad de México;

${ }^{10}$ Comunicación Social, Colegio de Medicina Interna de México, Ciudad de México;

${ }^{11}$ Presidente de la Asociación Mexicana de Infectología y Microbiología Clínica (AMIMC), Ciudad de México;

${ }^{12}$ Jefe de la División de Infectología del Instituto Nacional de Rehabilitación «Dr. Luis Guillermo Ibarra Ibarra», Ciudad de México

${ }^{13}$ Presidente del Colegio Mexicano de Reumatología, Ciudad de México;

${ }^{14}$ Director del Centro de Vacunación Prevenire, Hospital Star Médica, Morelia, Michoacán, México;

${ }^{15}$ Jefe del Servicio de Reumatología del Hospital Civil de Guadalajara «Fray Antonio Alcalde», Guadalajara, México;

${ }^{16}$ Jefe de Medicina Interna, SSA Hospital Rovirosa, Villahermosa, Tabasco, México;

${ }^{17}$ Médico adscrito al Departamento de Infectología Pediátrica del Hospital Español de México, Ciudad de México;

${ }^{18}$ Universidad Nacional Autónoma de México, Clínica para Niños con VIH/SIDA, Unidad de Investigación en Medicina Experimental, Ciudad de México;

${ }^{19}$ Consejo Directivo, Vocal admisión y filiales del Colegio de Medicina Interna de México, Ciudad de México;

${ }^{20}$ Presidente de la Sociedad Mexicana de Oncología (SMeO), Hospital General de México, Ciudad de México;

${ }^{21}$ Subdirector Médico del INER, Ciudad de México;

22 Presidente del Colegio de Medicina Interna de México, Ciudad de México;

${ }^{23}$ Médico adscrito, Subdirección Médica del INER, Ciudad de México;

${ }^{24}$ Presidente de la Federación Mexicana de Diabetes, Ciudad de México;

${ }^{25}$ Neumología Oncológica del INER, Ciudad de México;

${ }^{26}$ Director Médico de Cardiometabólica de San Juan del Río, Querétaro, México;

${ }^{27}$ Jefe del Servicio de Geriatría del Hospital Regional ISSSTE, León, Guanajuato, México;

${ }_{28}$ Médico adscrito al Departamento de Neumología del Hospital Ángeles Lomas, Ciudad de México;

${ }^{29}$ Médico adscrito al Departamento de Infectología del INCan, Ciudad de México;

${ }^{30}$ Jefa de la Subdivisión de Investigación Clínica, Profesor Titular B, Facultad de Medicina, Universidad Nacional Autónoma de México, Ciudad de México;

${ }^{31}$ Director General del Hospital General de Tijuana, Tijuana, México.
}

\author{
$\bowtie$ Autor para correspondencia: \\ Dra. Mayra Edith Mejía Ávila \\ Correo electrónico: medithmejia1965@gmail.com
}

Trabajo recibido: 6-II-2019; aceptado: 5-III-2019

Este artículo puede ser consultado en versión completa en: www.medigraphic.com/neumologia 
RESUMEN. La neumonía adquirida en la comunidad (NAC) es una infección frecuente, potencialmente grave que se asocia con elevada morbilidad y mortalidad, particularmente en adultos y en grupos vulnerables, a pesar de la investigación e información al respecto y del desarrollo de nuevos agentes antimicrobianos. El presente documento representa el esfuerzo de un grupo de expertos para divulgar el conocimiento sobre la prevención de la NAC a través de la vacunación neumocócica conjugada en adultos, especialmente en aquellos pacientes con comorbilidades como cardiopatías, neumopatías, diabetes mellitus, enfermedades reumáticas, cáncer e infección por el virus de la inmunodeficiencia humana $(\mathrm{VIH})$, entre otras. El objetivo de este documento es dar recomendaciones sobre la vacunación neumocócica conjugada a los médicos que atienden pacientes adultos con comorbilidades como las arriba mencionadas.

Palabras clave: Inmunización en adultos y adultos mayores, inmunocompromiso en adultos, neumonía adquirida en la comunidad, PCV13, prevención de la neumonía adquirida en la comunidad, vacuna neumocócica conjugada, vacunas.

\section{Pneumococcal conjugate vaccination in adults. Recommendations of the Medical Societies in Mexico}

ABSTRACT. Community-acquired pneumonia (CAP) is a frequent and potentially serious infection associated with high morbidity and mortality, particularly in adults and vulnerable groups, despite research and information and the development of new antimicrobial agents. This document represents the effort of a group of experts to disseminate knowledge about the prevention of CAP through pneumococcal conjugate vaccination in adults, especially in patients with comorbidities such as heart, lung and rheumatic diseases, diabetes mellitus, cancer and human immunodeficiency virus infection (HIV), among others. The objective is to provide recommendations on pneumococcal conjugate vaccination to physicians who treat adult patients with comorbidities such as those mentioned above.

Key words: Adult immunization, immunocompromised adults, community-acquired pneumonia, PCV13, community-acquired pneumonia prevention, neumococcal conjugate vaccine, vaccines.

\section{JUSTIFICACIÓN}

La neumonía adquirida en la comunidad (NAC) es una infección frecuente, potencialmente grave que se asocia con elevada morbilidad y mortalidad, particularmente en adultos y en grupos vulnerables, a pesar de la investigación e información al respecto y del desarrollo de nuevos agentes antimicrobianos. ${ }^{1}$

El presente documento representa el esfuerzo de un grupo de expertos para divulgar el conocimiento sobre la prevención de la NAC a través de la vacunación neumocócica conjugada en adultos, especialmente en aquellos pacientes con comorbilidades como cardiopatías, neumopatías, diabetes mellitus, enfermedades reumáticas, oncológicos e infección por el virus de la inmunodeficiencia humana (VIH), entre otras.

Este documento integra los conocimientos resultantes del análisis de la información bibliográfica disponible en el momento de la realización de estas recomendaciones, así como la revisión de las guías de práctica clínica nacionales e internacionales, revisiones y consensos y las propias experiencias de los médicos especialistas relacionados con el tema de la vacunación neumocócica conjugada en adultos desde las vertientes de cardiología, endocrinología, geriatría, infectología, medicina interna, neumología, oncología y reumatología.

Su contenido incluye una serie de recomendaciones sobre la vacunación neumocócica conjugada en adultos e, independientemente del grado de evidencia con el que se cuente para cada caso, se deja a criterio del médico, la valoración del estado de salud y el riesgo del paciente, decidir sobre la elegibilidad para recibir la vacuna. Este documento será de utilidad como apoyo en la toma de decisiones de los médicos generales y especialistas para la implementación de esta medida de prevención.

\section{Objetivo}

El objetivo de este documento es dar recomendaciones sobre la vacunación neumocócica conjugada a los médicos que atienden pacientes adultos con diabetes mellitus, con neumopatías, con enfermedades cardiovasculares, con enfermedades reumáticas, neoplásicas, con VIH, entre otras.

\section{LIMITACIONES DE LAS RECOMENDACIONES SEÑALADAS}

Este documento no tomó en cuenta la vacunación en la población pediátrica, sólo en adultos.

\section{ALCANCE}

Este documento está dirigido a médicos de diferentes especialidades que tratan pacientes adultos con comorbilidades como diabetes mellitus, neumopatías, enfermedades cardiovasculares, reumáticas, neoplásicas, $\mathrm{VIH}$, entre otras.

\section{CONFORMACIÓN DEL GRUPO DE TRABAJO}

Con la perspectiva de alcanzar un mayor conocimiento en lo referente a la vacunación neumocócica en pacientes adultos, se planteó integrar un grupo de 
trabajo con participantes profesionales de la salud; representados como miembros de las sociedades de: la Asociación Mexicana de Infectología y Microbiología Clínica, el Colegio de Medicina Interna de México, el Colegio Mexicano de Reumatología, el Colegio Nacional de Medicina Geriátrica, la Federación Mexicana de Diabetes y la Sociedad Mexicana de Oncología. Bajo el liderazgo de los representantes de la Sociedad Mexicana de Neumología y Cirugía de Tórax permitieron integrar los conocimientos y experiencias de médicos especialistas en cardiología, endocrinología, geriatría, infectología, medicina interna, neumología, oncología y reumatología para configurar este documento plasmado por un Medical Writer. El resultado del trabajo en equipo de los médicos convocados es el documento titulado Vacunación neumocócica conjugada en adultos. Recomendaciones de las Sociedades Médicas en México.

\section{METODOLOGÍA}

El presente documento se realizó con base en el análisis de la información bibliográfica disponible que los médicos participantes compartieron, así como la revisión de las guías de práctica clínica nacionales e internacionales, revisiones y consensos, y las propias experiencias de los médicos especialistas relacionados con el tema de la vacunación neumocócica conjugada en adultos publicados en idiomas inglés y español.

\section{POBLACIÓN OBJETIVO}

Adultos mayores de 18 años con factores de riesgo y/o comorbilidades como cardiopatías, neumopatías, diabetes mellitus, enfermedades reumáticas, neoplásica e infección con el virus de la inmunodeficiencia humana $(\mathrm{VIH})$, entre otras.

\section{Generalidades}

La neumonía adquirida en la comunidad (NAC) es una enfermedad común y potencialmente grave, la cual se asocia con alta morbilidad y mortalidad principalmente en adultos mayores y en personas con comorbilidades. ${ }^{1}$ La NAC es una de las causas más comunes para la admisión hospitalaria en América del Norte, representando más de 4.5 millones de visitas médicas, 1.1 millones de ingresos hospitalarios, un costo anual directo de $\$ 8$ mil millones de dólares y un costo anual adicional de $\$ 15,682$ dólares por atención médica en comparación con los pacientes que no tienen neumonía. ${ }^{2}$ Varios factores relacionados con el estilo de vida incrementan el riesgo de NAC, entre los que se incluyen el tabaquismo, el abuso de alcohol, tener bajo peso, tener contacto regular con niños, y mala higiene dental, entre otros. También la presencia de condiciones comórbidas, incluidas las enfermedades respiratorias crónicas, enfermedades cardiovasculares, cerebrovasculares, trastornos metabólicos, enfermedad de Parkinson, epilepsia, demencia, disfagia, infección por el virus de la inmunodeficiencia humana (VIH), enfermedad renal o hepática crónica han sido vinculadas a un mayor riesgo de NAC. ${ }^{3}$

El Streptococcus pneumoniae es una bacteria Gram positiva que forma parte de la flora de la nasofaringe. El fracaso de la inmunidad natural al $S$. pneumoniae conduce a la infección neumocócica y en algunos casos a la enfermedad neumocócica invasiva (ENI). Sin embargo, la manifestación más frecuente de la enfermedad neumocócica, es la neumonía neumocócica per se, donde el neumococo puede ser responsable de hasta $60 \%$ de los casos de NAC. ${ }^{4}$

Si bien, de manera fisiológica, las barreras mecánicas proporcionan la defensa inicial del tracto respiratorio filtrando los microorganismos de la corriente de aire a través de las vibrisas nasales, y las vías aéreas de ramificación sirven para evitar que los patógenos entren en el tracto respiratorio inferior (células epiteliales ciliadas y secreciones de las vías respiratorias). Cuando es rebasada la capacidad de los macrófagos alveolares para fagocitar los microorganismos, se traduce en neumonía clínica, desencadenándose una respuesta inflamatoria mediada por los macrófagos para reforzar las defensas, siendo este factor el que desencadena el síndrome clínico de neumonía. ${ }^{5}$

\section{Epidemiología de la NAC}

Las infecciones de las vías respiratorias bajas, entre las que se incluye a la neumonía, son una de las principales enfermedades en la lista de las primeras treinta causas de mortalidad a nivel mundial. ${ }^{6}$ El $40 \%$ de los pacientes con un episodio de neumonía adquirida en la comunidad (NAC), cuyo agente etiológico más común es el Streptococcus pneumoniae (S. pneumoniae), requieren ingreso hospitalario y alrededor del $10 \%$ necesitan ser admitidos en una Unidad de Cuidados Intensivos (UCI). ${ }^{1}$

\section{La NAC en México}

Hay pocos estudios poblacionales que evalúan la incidencia de la NAC, pero se estima que puede oscilar entre 1.6 y 13.4 casos por 1,000 habitantes/año, dependiendo del área geográfica analizada. ${ }^{1}$ El Instituto Nacional de Estadística y Geografía (INEGI) reportó, en 
el 2016, que las infecciones respiratorias agudas desde el año 2000 al 2013 fueron la primera causa de casos nuevos de enfermedad. ${ }^{7}$

En el año 2010, la tasa de morbilidad de neumonía y bronconeumonía fue de 144.50 por 100,000 habitantes, siendo una de las 20 primeras causas de morbilidad nacional ocupando el lugar 16, presentándose más frecuente en hombres. En el Instituto Nacional de Enfermedades Respiratorias, las neumonías en general constituyeron la tercera causa de morbilidad hospitalaria con 540 casos registrados en 2011 y, para ese mismo año, ocuparon el segundo lugar de mortalidad hospitalaria, con 70 defunciones. ${ }^{8}$

Como ya se mencionó, los estudios de estadística sobre la incidencia y prevalencia de la neumonía en México son escasos; sin embargo, en el estudio de epidemiología descriptiva sobre neumonía en adultos de Escobar-Rojas et al., se realizó una revisión de la información nacional sobre neumonía disponible en los anuarios de morbilidad de 1984 a 2010 del Centro Nacional de Vigilancia Epidemiológica y Control de las Enfermedades (CENAVECE) de la Secretaría de Salud; encontrando que las tasas de morbilidad de neumonía por grupo de edad, muestran en todos los casos una tendencia ascendente con cambios relativos, más pronunciados en los adultos de 45 a 64 años y en los de 65 o más años de edad. Los autores concluyeron que la morbilidad en ascenso y la mortalidad general no observa alguna tendencia asociada; sin embargo, suponen que las intervenciones para mejorar el control de esta enfermedad aún son insuficientes, por lo que es necesario fortalecer las medidas de prevención de neumonía mediante la vacunación. ${ }^{6}$

\section{Vacunación en México, resultados de la Encuesta Nacional de Vacunación en el Adulto Mayor (ENCOVAM, 2008) ${ }^{9}$}

La transición demográfica en México ha incrementado la demanda de servicios de salud por parte de la población de adultos mayores, quienes son más vulnerables a contraer cuadros infecciosos y de mayor severidad debido a mayor fragilidad fisiológica en este grupo poblacional, por lo que las autoridades de salud han buscado reforzar las estrategias de inmunización, particularmente contra influenza, neumococo, y tétanos. La Secretaría de Salud (SS) reportó que las infecciones respiratorias agudas durante 2005 , estuvieron entre las diez principales causas de morbilidad que afectaron a la población mayor de 60 años, además fueron la séptima causa de mortalidad.

En México, en el año 2007, la incidencia de neumonía y bronconeumonía en la población de 60 a 64 años fue de 206.7, y en personas de 65 y más años de 469.6 por 100,000 habitantes; siendo más frecuente en hombres que en mujeres. Para determinar la cobertura de vacunación para influenza, neumococo y tétanos, en adultos mayores de 60 años, el Instituto Nacional de Salud Pública (INSP) llevó a cabo la Encuesta Nacional de Cobertura de Vacunación (ENCOVAM 2008) en coordinación con el Centro Nacional de Vigilancia Epidemiológica y Control de Enfermedades (CENAVECE) de la SS, recabando la información durante abril y septiembre de 2008. El diseño de la muestra del estudio incluyó a los 32 estados de la República Mexicana, con capacidad de extrapolar la información al ámbito nacional y estatal.

\section{Prevención Primaria}

La inmunización previene enfermedades, discapacidades y defunciones por enfermedades prevenibles mediante la vacunación, tales como el cáncer cervical, la difteria, la hepatitis $B$, el sarampión, la parotiditis, la tos ferina, la neumonía, entre otras; es por ello que se le considera parte de la denominada Prevención Primaria. La Prevención Primaria incluye «todas aquellas medidas orientadas a evitar la aparición de una enfermedad o problema de salud, mediante el control de los factores causales y los factores predisponentes o condicionantes». El objetivo de las acciones de prevención primaria es disminuir la incidencia de la enfermedad. ${ }^{10}$

En 1977 se otorgó la autorización oficial a una vacuna neumocócica polisacárida, que protege contra 14 serotipos diferentes, y en 1983 se expandió para proteger contra 23, se denomina PPSV23, es más eficaz en adultos y no genera inmunidad de manera uniforme en niños menores de dos años de edad.11 En 1997 la ACIP recomendó el uso rutinario de la vacuna neumocócica PPSV23 en personas mayores de 65 años de edad, inmunocompetentes mayores de 2 años de edad con riesgo de enfermedad o muerte por neumococo debido a enfermedades crónicas, mayores de 2 años con asplenia, mayores de 2 años que viven en ambientes con alto riesgo y mayores de 2 años con inmunocompromiso. ${ }^{12}$

La PCV7 se agregó al programa de vacunación infantil en el año 2000, fue reemplazada por la PCV13 en el programa del año 2010. Desde la recomendación inicial, la enfermedad neumocócica invasiva en niños ha disminuido aproximadamente un $80 \%$ en Estados Unidos. En México, la PCV7 se introdujo en la Cartilla Nacional de Vacunación para niños en el año 2006. ${ }^{11}$

En el año 2010 se precalificó por la Organización Mundial de la Salud otra vacuna contra neumococo 
que protege contra 10 serotipos la PCV10 y que se ha introducido en algunos países del mundo como Brasil. ${ }^{13}$

En el año 2014, la ACIP, tras la evaluación de los resultados del estudio The Community-Acquired Pneumonia Immunization Trial in Adults (CAPiTA), modificó sus recomendaciones para incluir de forma sistemática una dosis de PCV13 en todos los adultos mayores de 65 años, independientemente de la presencia o no de factores de riesgo (tabla 1$).{ }^{14}$

\section{Generalidades de la vacuna neumocócica conjugada (PCV13) ${ }^{16}$}

La vacuna neumocócica conjugada (PCV13) contiene los siete polisacáridos capsulares neumocócicos existentes en la vacuna conjugada neumocócica heptavalente $(4,6 \mathrm{~B}, 9 \mathrm{~V}, 14,18 \mathrm{C}, 19 \mathrm{~F}, 23 \mathrm{~F})$ más seis polisacáridos adicionales (1, 3, 5, 6A, 7F, 19A), todos conjugados a la proteína transportadora (proteína de difteria CRM197). El mecanismo de acción es el siguiente: los linfocitos $B$ producen anticuerpos en respuesta a la estimulación antigénica por medio de mecanismos dependientes e independientes de los linfocitos T. La respuesta inmunológica a la mayoría de los antígenos es T-dependiente e incluye a la célula dendrítica que fagocita el antígeno y lo presenta a los linfocitos $T$ CD4+. Los linfocitos T CD4+ (células T cooperadoras) envían señales a los linfocitos $B$ directamente a través de interacciones de proteínas de la superficie celular, e indirectamente a través de la liberación de citocinas. Estas señales resultan en proliferación y diferenciación de los linfocitos $B$ hacia células plasmáticas y la producción de anticuerpos de alta afinidad. La señalización de linfocitos CD4+ T es un requisito para la generación de linfocitos B de larga vida llamados células plasmáticas, los cuales continuamente producen anticuerpos de diversos isotipos (con un componente $\lg \mathrm{G}$ ) y linfocitos $B$ de memoria que se movilizan rápidamente y secretan anticuerpos al volver a estar expuestos al mismo antígeno.

Los polisacáridos capsulares bacterianos (PS), aunque diferentes en estructura química, comparten la misma propiedad inmunológica de ser antígenos en gran medida T-independientes. En ausencia de la ayuda de linfocitos T, los linfocitos B estimulados por PS producen principalmente anticuerpos IgM; generalmente no hay maduración de la afinidad de anticuerpos y no se generan linfocitos $B$ de memoria. En el caso de las vacunas de polisacáridos que no están conjugados con proteínas, los PS se relacionan con pobre inmunogenicidad en lactantes menores de 24 meses de edad y con una falta de inducción de memoria inmunológica a cualquier edad. La conjugación de PS con una proteí- na transportadora permite que los PS desarrollen una respuesta dependiente de linfocitos $T$. Los linfocitos $\mathrm{T}$ específicos para proteínas transportadoras proporcionan las señales necesarias para la maduración de la respuesta de los linfocitos $B$ y la generación de memoria de los linfocitos B. La conversión de PS de $S$. pneumoniae a un antígeno T-dependiente por medio de la unión covalente a la proteína transportadora inmunogénica CRM197 refuerza la respuesta de anticuerpos e induce la memoria inmunológica. Se ha demostrado que lo anterior provoca respuestas de refuerzo al volver a exponer a los lactantes y niños pequeños a los polisacáridos neumocócicos.

La vacuna neumocócica 13-valente conjugada está indicada para prevenir enfermedad invasiva, neumonía y otitis media causada por los serotipos de S. pneumoniae 1, 3, 4, 5, 6A, 6B, 7F, 9V, 14, 18C, 19A, 19F y $23 \mathrm{~F}$ en lactantes, niños, adolescentes y adultos (tabla 2).

- Niños y adolescentes (5 a 17 años).

- Indicada para la prevención de enfermedad neumocócica (neumonía, enfermedad invasora y otitis media), causada por Streptococcus pneumoniae de las cepas mencionadas anteriormente, indicada especialmente en adolescentes con riesgo.

- Adultos de 18 a 49 años con uno o más factores de riesgo.

- Indicada para la prevención de enfermedad neumocócica (neumonía y enfermedad invasora), causada por Streptococcus pneumoniae de los serotipos arriba mencionados.

En adultos de 50 a 64 años de edad, se deben evaluar los factores de riesgo para indicar la vacunación para la prevención de la enfermedad neumocócica (neumonía y enfermedad invasora), causada por Streptococcus pneumoniae de los serotipos arriba mencionados.

Las contraindicaciones reportadas en la información para prescribir de PCV13 son hipersensibilidad a cualquier componente de la vacuna, incluido el toxoide diftérico y no se recomienda su uso en mujeres embarazadas ni en pacientes con infecciones activas.

\section{Vacunación en el adulto}

La protección proporcionada por las vacunas durante la infancia disminuye con la edad. El concepto de inmunosenescencia se define como «los cambios que reducen la protección de las vacunas como resultado del envejecimiento y los efectos de éste sobre las in- 
Edad

Indicaciones

Serotipos

Contraindicaciones

Respuesta inmunológica
Conjugada: un tipo de vacuna en la que se une una proteína a parte de la bacteria para mejorar la protección que proporciona la vacuna ${ }^{\mathrm{a}}$

\section{6 semanas de edad a 17 años}

Adultos de 18 a 49 años con uno o más factores de riesgob

Adultos $\geq 50$ años con uno o más factores de riesgo

\section{Inmunodeficiencia}

Enfermedad renal o función renal deficiente

Esplenectomía o asplenia funcional

Enfermedad cardíaca

Enfermedad pulmonar obstructiva crónica

Alcoholismo crónico

Diabetes (tipo 1 o tipo 2)

Enfermedad hepática crónicae

$$
\text { 1, 3, 4, 5, 6A, 7F, 9V, 14, 18C, 19A, 19F, 23F, }
$$
$6 \mathrm{~B}^{\mathrm{b}}$

Hipersensibilidad a cualquier componente de la vacuna

No se recomienda su uso en mujeres embarazadas ni en infecciones activas ${ }^{\mathrm{b}}$

Los linfocitos $B$ producen anticuerpos en respuesta a la estimulación antigénica por medio de mecanismos dependientes e independientes de los linfocitos $T$ (T-dependientes y T-independientes). La respuesta inmunológica a la mayoría de los antígenos es T-dependiente e incluye la colaboración de linfocitos T CD4+ y linfocitos $B$, reconociendo el antígeno en forma ligada. Los linfocitos T CD4+ (células T-- colaboradoras) envían señales a los linfocitos $B$ directamente a través de interacciones de proteínas de la superficie celular, e indirectamente a través de la liberación de citocinas. Estas señales resultan en proliferación y diferenciación de los linfocitos B y la producción de anticuerpos de alta afinidad. La señalización de linfocitos CD4+ $T$ es un requisito para la generación de linfocitos $B$ de larga vida llamados células plasmáticas, las cuales continuamente producen anticuerpos de diversos isotipos (con un componente $\lg G$ ) y linfocitos $B$ de memoria que se movilizan rápidamente y secretan anticuerpos al volver a estar expuestas al mismo antígeno ${ }^{b}$
Polisacárida: un tipo de vacuna en la que se simula la superficie de ciertas bacterias para ayudar al cuerpo a desarrollar una protección contra esos microbios ${ }^{\mathrm{a}}$

No se usa en niños menores de 2 años

Se recomienda para las personas mayores de 2 años de edad con un alto riesgo de infección para prevenir neumonía neumocócica e infecciones neumocócicas sistémicas causadas por los serotipos los serotipos incluidos en la vacunac $\geq 65$ años $^{d}$

Inmunodeficiencia

Enfermedad renal o función renal deficiente

Esplenectomía o asplenia funcional

Enfermedad cardíaca

Enfermedad pulmonar obstructiva crónica

Alcoholismo crónico

Diabetes (tipo 1 o tipo 2)

Enfermedad hepática crónica ${ }^{e}$

1, 2, 3, 4, 5, 6B, 7F, 8, 9N, 9V, 10A, 11A, 12F, 14, $15 \mathrm{~B}, 17 \mathrm{~F}, 18 \mathrm{C}, 19 \mathrm{~A}, 19 \mathrm{~F}, 20,22 \mathrm{~F}, 23 \mathrm{~F}$ y $33 \mathrm{~F}^{\mathrm{d}}$

Hipersensibilidad a cualquiera de los componentes de la vacuna

El uso de la vacuna se debe aplazar en caso de alguna enfermedad febril significativa, infección activa o recaída de una enfermedad crónica

No está recomendada en personas que han sido vacunados en los últimos 3 años ${ }^{d}$

Induce anticuerpos específicos del tipo que mejoran la opsonización, la fagocitosis y la muerte de neumococos por leucocitos y otras células fagocíticas. Los niveles de anticuerpos que se correlacionan con protección contra la enfermedad neumocócica no han sido claramente definidos.

La vacuna preparada de bacterias termoinactivadas, han demostrado la inmunogenicidad de los polisacáridos capsulares neumocócicos, su heterogenicidad antigénica y la actividad protectora de los anticuerpos dirigidos contra los polisacáridos capsulares en animales y en el hombre.

Las respuestas de anticuerpos a la mayoría de los tipos capsulares neumocócicos son generalmente bajas o inconsistentes en niños menores de 2 años de edad.c Los polisacáridos capsulares bacterianos (PS), aunque diferentes en estructura química, comparten la misma propiedad inmunológica por ser antígenos en gran medida T-independientes. En ausencia de la ayuda de linfocitos $T$, los linfocitos $B$ estimulados por PS producen principalmente anticuerpos IgM; generalmente no hay maduración de la afinidad de anticuerpos y no se generan linfocitos B de memoria. ${ }^{\mathrm{c}, \mathrm{d}}$ 


\begin{tabular}{|c|c|c|}
\hline \multicolumn{3}{|c|}{ Continúa de la Tabla 1: Diferencias entre PCV13 y PPSV23. ${ }^{15-20}$} \\
\hline & PCV13 & PPSV23 \\
\hline Otros & $\begin{array}{l}\text { El estudio The Community - Acquired Pneumonia } \\
\text { Immunization Trial in Adults (CAPiTA), se llevó a } \\
\text { cabo de acuerdo con los requisitos de la vía de } \\
\text { aprobación acelerada de la Food and Drug Ad- } \\
\text { ministration (FDA, Administración de Alimentos y } \\
\text { Medicamentos de Estados Unidos) para medir la } \\
\text { eficacia de la vacuna PCV13 en adultos mayores. }\end{array}$ & \\
\hline \multicolumn{3}{|c|}{$\begin{array}{l}\text { Adaptado de: } \\
\text { a https://www.cdc.gov/pneumococcal/vaccination-sp.html } \\
\text { b Información para prescribir de Prevenar }{ }^{\circledR} 13 V \\
\text { c Pletz MW, et al. Int J Antimicrobial Agents. 2008;32:199-206. } \\
\text { d Información para prescribir Pneumo23 http://www.medicamentosplm.com/Home/productos/pneumo_23_solucion_inyectable/161/101/ } \\
\text { 9308/162 } \\
\text { e https://www.cdc.gov/vaccines/schedules/downloads/adult/adult-schedule-easy-read.pdf } \\
\text { f Suaya JA, et al. Vaccine. 2018;36:1477-1483 }\end{array}$} \\
\hline
\end{tabular}

\section{Tabla 2: Esquemas de dosis recomendados. ${ }^{16}$}

\begin{tabular}{c|c} 
Inmunización & $\begin{array}{c}\text { Esquema para ponerse } \\
\text { primaria }\end{array}$ \\
al día «Catch-up \\
immunization»
\end{tabular}

Niños mayores a 24 meses a 5 años de edad

Una dosis

Tres dosis a los 2, 4, y 6 meses de edad y una cuarta de refuerzo entre los 12 y 15 meses de edad

Se recomienda que los lactantes que reciban una primera dosis de Prevenar $^{\circledR} 13 \mathrm{~V}$ completen el ciclo de vacunación con PCV13
Pacientes que hayan o no sido vacunados

Niños entre 24 meses a 5 años de edad y los niños de 6 a 17 años

Dosis única hayan o no sido vacunados previamente con una o más dosis de vacuna neumocócica conjugada 7-valente
Adultos $\geq$ de

18 años de edad

Adultos de 18 años y mayores

Dosis única incluyendo aquellos que ya han sido vacunados con una vacuna conjugada neumocócica polisacárida

Adaptado de: Información para prescribir Prevenar ${ }^{\circledR}$ 13V.

munidades naturales y adquiridas». ${ }^{21}$ La vacunación durante todo el curso de vida, como se menciona en el Primer Consenso Mexicano de Vacunación en el Adulto, se convierte tanto en una protección individual que ofrece cada una de las vacunas a lo largo de la vida como en una protección colectiva, incluso con efecto en las siguientes generaciones. ${ }^{22}$

Los factores de riesgo para padecer la neumonía adquirida en la comunidad son los siguientes: ${ }^{23}$
- Los extremos de la edad (menores de 2 años y mayores de 65).

- Es más frecuente en hombres.

- Ciertos tipos de población (varios grupos raciales o étnicos).

- Estilo de vida (consumo excesivo de alcohol y de fumar).

- Condiciones médicas y enfermedades concomitantes subyacentes que aumentan el riesgo de enfermedad neumocócica invasiva y su evolución tales como: ${ }^{14}$ 
- Aquéllas que conllevan un estado de déficit inmunitario, alteraciones de las defensas locales del órgano diana.

- Enfermedades cardiorrespiratorias crónicas.

- Trastornos renales crónicos.

- Condiciones hepáticas.

- Diabetes mellitus.

- Enfermedades neoplásicas/pacientes en tratamiento con quimioterapia, tumor sólido o hematológicos.

- Infección por el virus de la inmunodeficiencia humana.

- Pacientes en espera de trasplante de órgano sólido y trasplantados de órgano sólido y/o hematopoyético.

- Pacientes con enfermedad autoinmune y tratados con corticoides, inmunosupresores o con productos inmunobiológicos.

- Pacientes con fístulas de líquido cefalorraquídeo.

- Pacientes con implantes cocleares.

- Abuso de alcohol (relación dosis-dependiente).

- Medicamentos (uso de corticoesteroides inhalados, inhibidores de la bomba de protones).

- Factores de riesgo adicionales asociados con la infección por neumococo como mieloma, hipogammaglobulinemia (deficiencia de lgG2), esplenectomía o asplenia «funcional» (como en la anemia drepanocítica).

Para conocer la eficacia de la vacuna PCV13, se llevó a cabo el Community -Acquired Pneumonia Immunization Trial in Adults (CAPiTA), un estudio aleatorizado, doble-ciego, controlado con placebo, con grupo paralelo, que incluyó más de 84,000 adultos de más de 65 años de los países bajos. Los pacientes fueron aleatorizados para recibir ya fuera placebo o PCV13 (inyección intramuscular en el deltoides derecho). El objetivo principal fue mostrar la eficacia de la vacuna PCV13 en la prevención de un primer episodio de neumonía adquirida en la comunidad confirmada por hallazgos clínicos, radiográficos y prueba de antígeno urinario positivo para el tipo de vacuna o aislamiento de $S$. pneumoniae de tipo vacuna de la sangre u otro sitio estéril, y los objetivos secundarios eran mostrar la eficacia de PCV13 en la prevención de un primer episodio confirmado de NAC no bacteriémica y no invasiva (es decir, un episodio de NAC para el cual el resultado de un hemocultivo y de cultivos de cualquier otro sitio estéril fueran negativos para $S$. pneumoniae) y la enfermedad neumocócica invasiva (es decir, un episodio en el que se detecta la presencia de $S$. pneumoniae en un sitio estéril). Los pacientes fueron seguidos durante un período de 5 años, para vigilar episodios de NAC.
La media de seguimiento para ambos grupos fue de 3.97 años y la tasa de abandono fue de $12.4 \%$ para el grupo de PCV13, y de $12.6 \%$ para el grupo placebo. Se encontró que la vacuna tiene una eficacia significativa contra los primeros episodios confirmados de NAC, NAC confirmada no bacteriémica y no invasiva y en enfermedad neumocócica invasiva. ${ }^{24}$

También se encontró que la vacuna PCV13 tuvo una eficacia significativa con respecto a la NAC, a la NAC confirmada no bacteriémica y no invasiva, y a la enfermedad neumocócica invasiva en la población de intención de tratar modificada. Vale la pena comentar que no se presentaron eventos adversos de consideración en los 42,000 pacientes a los que se les aplicó PCV13.

En el análisis post hoc se observó que la eficacia de la vacuna inició poco después de la vacunación y que esta eficacia se mantuvo durante aproximadamente 4 años, sin evidencia de disminución; lo que probablemente se debió a la memoria inmune mediada por la vacuna PCV13. ${ }^{24}$

Dado que en el estudio CAPiTA sólo se evaluó la eficacia de la vacuna PCV13 en adultos mayores de 65 años, resultando en una eficacia superior al placebo, se decidió llevar a cabo el análisis post hoc, cuyo objetivo principal fue evaluar la eficacia de la vacuna PCV13 contra un primer episodio de NAC de serotipo tipo vacuna (VT-CAP) en participantes en riesgo según el análisis de eficacia de la población por protocolo, de acuerdo al estudio original. En este análisis solamente se reclutaron adultos mayores inmunocompetentes, los cuales fueron definidos como aquellos individuos con condiciones crónicas sin inmunocompromiso, (denominadas «en riesgo») como enfermedad cardíaca, enfermedad pulmonar (incluye enfermedad pulmonar obstructiva crónica [EPOC] y asma), diabetes, enfermedad hepática y tabaquismo, patologías con alta prevalencia en la población adulta y que presentan un mayor riesgo de desarrollar neumonía y enfermedad neumocócica. Los participantes fueron clasificados como «en riesgo» si tenían una o más de las condiciones médicas mencionadas, excepto esplenectomizados y aquellos pacientes sin ninguna condición médica fueron clasificados como «sin riesgo conocido". Se incluyeron los datos de 41,385 pacientes en riesgo y de 42,679 sin riesgo conocido. Dentro de los resultados más relevantes, se encontró que la incidencia de VT-CAP en los participantes en riesgo fue 4.2 veces mayor que en los participantes sin riesgo conocido (88.2 frente a 21.1 episodios por 100,000 persona/año) y que la protección de la vacuna continuó durante un promedio de 3.95 años en los participantes en riesgo y de 4 años en aquéllos sin riesgo conocido. El estudio CAPiTA también demostró 
que la vacuna PCV13 provocaba no sólo aumentos significativos y duraderos en los títulos de la actividad opsonofagocítica (OPA, por sus siglas en inglés) sino también en las concentraciones de inmunoglobulina $G$ para los 13 serotipos, lo que pone en evidencia la actividad inmunogénica de la vacuna PCV13 en adultos con y sin condiciones médicas crónicas subyacentes y que, inclusive, dada la eficacia contra VT-CAP en adultos mayores en riesgo, su uso puede extenderse a adultos en riesgo menores de 65 años. ${ }^{20}$

Las estrategias de inmunización contra el neumococo varían con respecto a los grupos de edad, los grupos de riesgo y el tipo de vacuna utilizada (PPSV23, PCV13 o ambas). De acuerdo con la evidencia epidemiológica disponible, la mejor estrategia de inmunización antineumocócica para reducir la carga de infecciones de vías respiratorias bajas debe sustentarse en la edad y en los factores de riesgo. ${ }^{22}$

\section{Recomendaciones de las sociedades médicas: vacunación en diferentes poblaciones con comorbilidades y su impacto}

Las estrategias de inmunización contra neumococo varían con respecto a los grupos de edad, los grupos de riesgo y el tipo de vacuna utilizada (PCV13 y/o PPSV23). Con base en la evidencia epidemiológica disponible, la mejor estrategia de inmunización neumocócica para reducir la carga de infecciones de vías respiratorias bajas, debe sustentarse en la edad y los factores de riesgo. De hecho, aunque la estrategia de riesgo tiene muchas desventajas como la dificultad de acceso a los servicios de salud, la participación necesaria de diferentes profesionales de la salud y la dificultad para lograr una cobertura elevada de ésta, debe implementarse a gran escala y asociarse a la estrategia de la edad. Es por ello que en agosto de 2014, la ACIP recomendó el uso rutinario de una dosis de PCV13 seguida de una dosis de PPSV23. EI intervalo para la aplicación entre una y otra vacuna de acuerdo a las últimas recomendaciones del mismo Comité recién publicadas en febrero de 2016, es de un año o más y consisten en lo siguiente: para adultos $\geq$ de 65 años inmunocompetentes sin ninguna inmunización previa, se debe aplicar una dosis de PCV13, seguida de una dosis de PPSV23 después de un año. Este mismo esquema se recomienda en pacientes menores de 65 años con padecimientos crónicos o con algún tipo de inmunosupresión. Si antes de los 65 años un paciente inmunocompetente que ya recibió alguna dosis de la vacuna PPSV23 en algún momento de su vida, a partir de los 65 años se le puede administrar una dosis de PCV13 y otra de PPSV23 después de un año, siempre y cuando hayan pasado al menos 5 años desde la primera administración de PPSV23.

EI ACIP actualmente recomienda que se administre tanto la vacuna antineumocócica conjugada 13 valente como la vacuna antineumocócica polisacárida 23 valente a todos los adultos inmunocompetentes con edad mayor o igual a 65 años, sugiriendo que primero se administra la vacuna PCV13 seguido de PPSV23, seis a doce meses después. Dicho Comité también recomienda que los adultos mayores o igual a 65 años que ya recibieron una dosis de PPSV23, también reciban una dosis de PCV13 un año después de la dosis de PPSV23 (figura 1). ${ }^{25}$ El presente documento recomienda seguir dicho esquema modificando la edad a partir de los 50 años con factores de riesgo.

\section{a) Vacunación en pacientes diabéticos}

En México, la Secretaría de Salud junto con el Comité Nacional de Seguridad en Salud, a través del Subcomité de Enfermedades Emergentes, emitió la declaratoria de emergencia epidemiológica para todo el territorio nacional, ante la magnitud y trascendencia de los casos de diabetes mellitus, ${ }^{26}$ por lo que se ha convertido en un grave problema de salud pública, no sólo en México, sino también en el mundo. Según la Organización Mundial de la Salud (OMS), la tasa de mortalidad debida a las infecciones neumocócicas tiene un promedio del $10-20 \%$, pudiendo exceder el $50 \%$ en los grupos de alto riesgo. Se estima que las personas con diabetes tienen casi tres veces más riesgo de muerte debido a complicaciones relacionadas con la neumonía y los pacientes con diabetes tipo 1 y tipo 2 tienen un riesgo de 4.4 y 1.2 veces de hospitalizaciones relacionadas con la neumonía, respectivamente. También se ha observado que en pacientes con diabetes con una hemoglobina glucosilada (HbA1c) mayor de $9 \%$, tienen un $60 \%$ más de riesgo de hospitalización relacionado con la neumonía ${ }^{27}$

La diabetes mellitus está relacionada con una alteración inmunológica, principalmente por una alteración en las defensas del huésped y es considerada un factor de riesgo independiente para desarrollar infecciones del tracto respiratorio, incluyendo la neumonía. ${ }^{27,28}$

En los pacientes con diabetes se han reportado alteraciones en las poblaciones de neutrófilos, monocitos y linfocitos. La disminución del contenido de C4 en pacientes diabéticos puede estar asociada con neutrófilos disfuncionales y una menor respuesta de las citocinas. Las células mononucleares y los monocitos en estos pacientes liberan cantidades más bajas de interleucina-1 (IL-1) e interleucina-6 (IL-6) 
Vacunación neumocócica a personas vírgenes a exposición vacunal mayores a 65 años

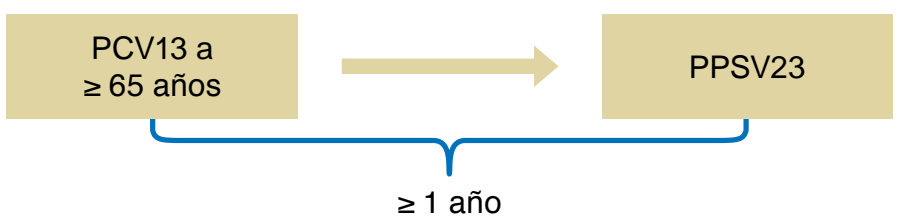

Personas que previamente fueron vacunadas con PPSV23 en mayores de 65 años

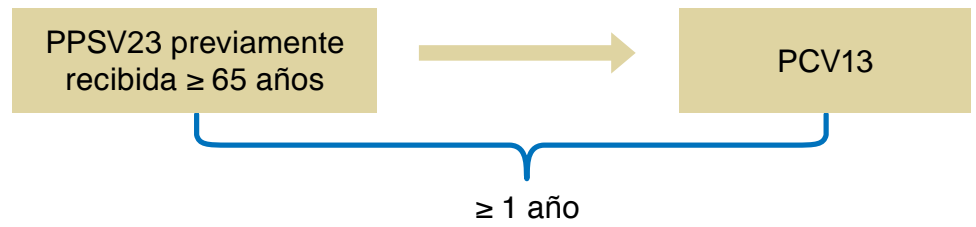

Personas que previamente fueron vacunadas con PPSV23 antes de los 65 años y que ahora son $\geq$ a 65 años

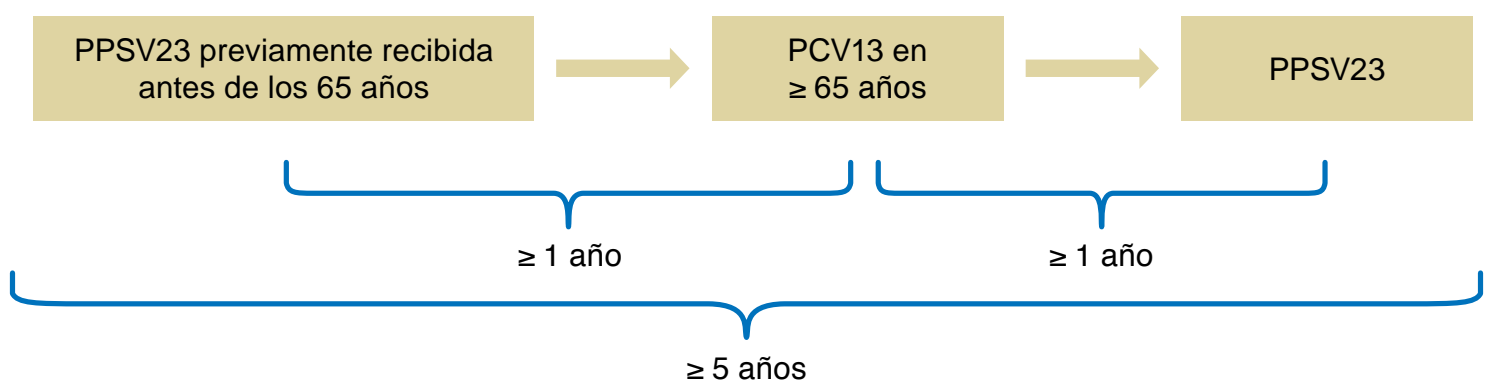

Adaptado de: https://www.cdc.gov/mmwr/preview/mmwrhtml/mm6434a4.htm?s_cid=mm6434a4_w

Figura 1: Esquema de intervalos de vacunación neumocócica entre PCV13 y PPSV23. ${ }^{25}$

en respuesta a la estimulación por lipopolisacáridos (LPS), que se activa en el proceso de fagocitosis. El aumento de la glicosilación puede inhibir la producción de IL-10 por linfocitos y macrófagos. Además, se reduce la cantidad de interferón gamma (IFN- $\gamma$ ) liberado por las células $T$ y las células NK y el factor de necrosis tumoral (TNF- $\alpha$ ) liberado por las células T y los macrófagos. La hiperglucemia crónica por sí misma influye sobre diversas funciones de defensa del huésped, reduciendo la movilización de los leucocitos polimorfonucleares, la quimiotaxis y la actividad fagocítica. ${ }^{27}$ De tal manera, que la capacidad de activación del sistema de complemento a través de la vía clásica se encuentra disminuida en la diabetes, lo que podría contribuir al aumento en la susceptibilidad a las infecciones. La protección inmunológica contra la enfermedad neumocócica está mediada a través de anticuerpos opsonofagocíticos dirigidos contra los polisacáridos capsulares bacterianos. ${ }^{29}$
Los pacientes con enfermedad renal crónica estadío 3, que además tienen diabetes mellitus, son considerados inmunosuprimidos, mientras que los pacientes con diabetes mellitus con tratamiento hipoglucemiante oral o insulinodependientes son considerados inmunocompetentes. En el grupo de pacientes en riesgo que padecen diabetes, se ha observado un incremento de la tasa de incidencia de padecer neumonía neumocócica conforme se incrementa la edad, siendo más alto en el grupo de más de 65 años. ${ }^{14}$ Entre los pacientes inmunocompetentes, se observó una mayor eficacia de la vacuna PCV13 en pacientes con diabetes mellitus, comparado con aquellos pacientes que no tienen diabetes. En el análisis post hoc del estudio CAPITA, la eficacia de la vacuna PCV13 en el adulto mayor, fue modificada por la presencia de diabetes mellitus en el momento de la vacunación, con una eficacia de la vacuna más alta para los sujetos con DM que los que no. ${ }^{29}$ 


\section{Recomendaciones para pacientes con diabetes}

Debido a que las personas con diabetes pueden tener un mayor riesgo de infección neumocócica, e inclusive se ha mencionado que tienen un alto riesgo de bacteriemia nosocomial, con una tasa de mortalidad de hasta el 50\%, la Asociación Americana de Diabetes (ADA) recomienda la vacunación contra la neumonía para todos los adultos mayores de 65 años, administrando la vacuna antineumocócica conjugada (PCV13), seguida de una dosis de PPSV23 al menos un año después o bien administrar la vacuna conjugada PCV13, 5 años después de la última dosis de PPSV23. ${ }^{30}$ En adultos mayores de 19 años en adelante (recomendación de ACIP) se puede evaluar la necesidad de vacunar con una dosis de PCV13. ${ }^{31}$

\section{b) Vacunación en pacientes con neumopatías}

Tomando en cuenta las recomendaciones de la Sociedad de Enfermedades Infecciosas de América (IDSA), de la Sociedad Torácica Americana (ATS) y de ACIP, el grupo de neumólogos que participaron en la realización de este documento recomienda lo siguiente:

De acuerdo con la evidencia científica actual, y considerando la epidemiología de la población, en el presente documento se recomienda la vacunación contra neumococo con la PCV13 en adultos mayores de 19 años en adelante (recomendación de ACIP). Se puede evaluar la necesidad de vacunar con una dosis de PCV13 de acuerdo al riesgo que presente el paciente.

- En los casos en que sea posible de acuerdo con la disponibilidad de la vacuna PCV13, se puede seguir el algoritmo de vacunación sugerido por el Comité Asesor sobre Prácticas de Inmunización (ACIP, por sus siglas en inglés), con una dosis de PCV13 seguida de una dosis de PPSV23 con los intervalos sugeridos por el mismo comité.

- Personas de 2 a 60 años con enfermedades crónicas de tipo cardiovascular, pulmonar, diabetes, alcoholismo, cirrosis, o con fístulas de líquido cefalorraquídeo, se indica 1 dosis sin revacunación.

- Personas de 2 a 60 años con asplenia funcional o anatómica (en el caso de esplenectomía selectiva, la vacuna debe administrarse por lo menos dos semanas antes de la cirugía), se indica 1 dosis con 1 sola revacunación 5 años después de la primera dosis en los pacientes mayores de 10 años, o 3 años después de la primera en los pacientes menores de 10 años.
- Personas mayores de 2 años con inmunosupresión (incluyendo: infección asintomática o sintomática por VIH, leucemia, linfoma, enfermedad de Hodgkin, mieloma múltiple, neoplasias diseminadas, insuficiencia renal crónica, síndrome nefrótico) se indica 1 dosis con 1 sola revacunación 5 años después de la primera dosis en los pacientes mayores de 10 años, o 3 años después de la primera en los pacientes menores de 10 años. En el caso de que el paciente reciba algún tipo de terapia inmunosupresora, la administración de la vacuna será hasta dos semanas después de haber recibido dicha terapia.

- Personas de 2 a 60 años inmunocompetentes que residen en casas de cuna o asilos. No requieren revacunación.

- Evaluar las comorbilidades y las condiciones de todos los pacientes hospitalizados por neumonía para recibir una dosis de PCV13 antes de su egreso. ${ }^{8}$ No requieren revacunación.

- Se puede aplicar simultáneamente con la vacuna de la influenza.

- Dejar de fumar debería ser un objetivo para las personas hospitalizadas con NAC que fuman. (Recomendación moderada, nivel de evidencia III)

- Los fumadores que no dejan de fumar también deben vacunarse contra el neumococo y la influenza. (Recomendación débil, nivel de evidencia III)

Todos los pacientes con neumopatías crónicas deben ser valorados sobre su estatus vacunal al momento del diagnóstico y, en su caso, recibir una recomendación para vacunación. Los casos imperdibles de vacunación deben englobar a los siguientes grupos de entidades:

a) Pacientes con EPOC panel D (guías GOLD/cuadro por panel), paciente con exacerbaciones frecuentes, que en relación con el manejo establecido requieren el uso de esteroides sistemáticos o inhalados por lo que corren el riesgo de desarrollar NAC con mayor frecuencia al resto de los pacientes con la misma entidad.

b) Asma de difícil control, o aquellos que han presentado exacerbación grave con estancia en terapia intensiva con o sin ventilación mecánica.

c) Pacientes con fibrosis pulmonar idiopática, al momento del diagnóstico.

d) Cualquier enfermedad pulmonar intersticial difusa, independientemente de la edad y causa, quienes en su manejo recibirán esteroide, inmunosupresión o terapia biológica.

e) Bronquiectasias, con cuadros recurrentes de infección, que han requerido o no hospitalización por agudización del cuadro respiratorio. 


\section{c) Vacunación en pacientes con enfermedades cardiovasculares}

Entre los principales factores que precipitan las descompensaciones y hospitalizaciones en pacientes con insuficiencia cardíaca congestiva (ICC), destacan la no adhesión al tratamiento, la isquemia miocárdica aguda, la presión arterial elevada y las infecciones respiratorias (neumonía y enfermedades virales principalmente). La congestión pulmonar está presente en gran parte de los pacientes con insuficiencia cardíaca y predispone a infecciones respiratorias y se ha observado que en un ambiente hospitalario, los pacientes con ICC tienen un riesgo mayor de infecciones pulmonares, en especial neumonía. Otro dato que llama la atención es que la tasa de vacunación contra influenza y neumococo en estos pacientes es muy baja y aún es menor en aquellos pacientes descompensados atendidos en el Servicio de Urgencias. ${ }^{32}$

En el estudio retrospectivo de Bornheimer et al, de los 827,902 pacientes que reunieron los criterios para ICC y que fueron incluidos en la población de estudio, el 4.6\% (38,010 pacientes) experimentaron un nuevo episodio de NAC y de estos el $87 \%$ requirió tratamiento intrahospitalario, siendo la mayoría mayores de 65 años. El $41 \%$ de los pacientes tenían al menos una comorbilidad crónica, mientras que el $44.8 \%$ tenían alguna condición de inmunocompromiso y el $37.3 \%$ tuvieron una hospitalización dentro del año anterior. Se encontró que aquellos pacientes con ICC diagnosticados con un episodio de NAC, tuvieron $45 \%$ más probabilidades de experimentar una exacerbación de su condición preexistente comparados con aquellos pacientes con ICC y EPOC que no desarrollaron NAC. Otro hallazgo fue la identificación del papel de la inflamación (medición de interleucina 6) como predictor del aumento de riesgo de mortalidad cardiovascular dentro de un año de seguimiento. Estos hallazgos vinculan la NAC con los efectos adversos a largo plazo en las enfermedades cardíacas, observándose un mayor riesgo de exacerbaciones entre los 40 a 64 años de edad, así como en adultos mayores con insuficiencia cardíaca o con múltiples comorbilidades. La prevención de la neumonía en pacientes con enfermedades cardíacas podría alterar los resultados a largo plazo y además se deben abordar los mecanismos subyacentes, como la inflamación crónica y/o la activación plaquetaria, ya que podrían alterar la frecuencia de las exacerbaciones de la insuficiencia cardíaca o la EPOC. ${ }^{33}$

En otro estudio, se observó que de los pacientes hospitalizados por neumonía, 206 (34.85\%) tuvieron eventos cardiovasculares en un período mayor a 10 años después de la hospitalización por neumonía. De éstos, 104 casos (50.5\%) tuvieron infarto de miocardio, 35 casos (17\%) tuvieron ataque cardíaco y 67 (32.5\%) tuvieron eventos coronarios mortales. El numero acumulado de casos de neumonía que presentaron eventos cardiovasculares a los 30 días después del cuadro de neumonía fueron de 68 (11.5\%); a los 90 días, 79 (13.4\%); al año, 106 (17.9\%); y a los 5 años, 177 (30.0\%). A pesar de que el $80 \%$ de los pacientes hospitalizados por neumonía se recuperan en una semana, la mitad de estos pacientes tienen marcadores inflamatorios circulatorios altos. Los niveles altos de interleucina 6 al momento del alta hospitalaria se asocian con un aumento de la mortalidad cardiovascular un año después de la neumonía. Por lo tanto, la inflamación persistente después de la neumonía puede contribuir a la progresión de la enfermedad cardiovascular. Del mismo modo, los sobrevivientes a la hospitalización por neumonía también pueden tener un estado de procoagulación persistente y niveles altos en los marcadores de coagulación al alta hospitalaria que se han asociado con un mayor riesgo de muerte cardiovascular. La hospitalización por neumonía se asocia con un aumento del riesgo de enfermedad cardiovascular a corto y largo plazo, por lo que se sugiere que la neumonía es un factor de riesgo importante para presentar enfermedad cardiovascular. ${ }^{34}$

Dentro de las medidas que se sugieren para prevenir la NAC están la suspensión del tabaquismo, la vacunación contra la influenza y contra la enfermedad neumocócica, ${ }^{32}$ ya que se ha observado que la vacunación contra la influenza y contra el neumococo disminuyó la mortalidad global y cardiovascular en adultos mayores añosos, además de reducir el riesgo de hospitalizaciones por neumonía o muerte de todas las causas. ${ }^{33}$

La vacunación ha sido relacionada con beneficios, tales como la disminución de eventos coronarios (tanto en la prevención primaria como en la secundaria), reducción de los accidentes cerebrovasculares, disminución en las hospitalizaciones y costos por otras enfermedades, disminución de la mortalidad y morbilidad en todas las edades con factores de riesgo, principalmente entre adultos mayores añosos. ${ }^{32}$ La prevención de la neumonía en pacientes con enfermedad cardíaca y pulmonar puede cambiar los resultados a largo plazo. ${ }^{33}$

\section{d) Vacunación en pacientes con enfermedades reumáticas}

Tanto la artritis reumatoide (AR) como el lupus eritematoso sistémico (LES) se asocian con un exceso de mortalidad de 2 a 4 veces, así como otras enfermedades reumáticas incluyendo las espondiloartropatías y las vasculitis entre otras, siendo la infección bacteriana la 
principal causa de mortalidad en estos pacientes. Es importante considerar que además existen enfermedades reumáticas con mayor afectación pulmonar, lo cual incrementa el riesgo de la infección per se.

Dentro de las infecciones bacterianas, la neumonía causa entre el 15 y $25 \%$ de las muertes, por lo que la prevención de la infección bacteriana, que es una de las causas principales de morbilidad en pacientes con artritis reumatoide (AR) y lupus eritematoso sistémico (LES), es una prioridad, sin embargo, aún no queda claro la seguridad y eficacia de la vacuna contra neumococo en estos pacientes. ${ }^{35}$

Como ya se mencionó, los pacientes con enfermedades reumáticas inflamatorias autoinmunes, tienen un mayor riesgo de enfermedades infecciosas y sus complicaciones, no sólo debido a la naturaleza de sus enfermedades en donde la inmunidad juega un papel importante, sino por los medicamentos inmunosupresores que toman de manera rutinaria y aumentan el riesgo e inclusive tienen 1.7 veces el riesgo de adquirir infecciones, las cuales en la mayoría de las veces son prevenibles mediante la vacunación. ${ }^{36}$

La eficacia de la vacunación contra neumococo ha sido un punto de interés en varios artículos. Algunos de ellos comentan que la eficacia es difícil de determinar y que en AR se han reportado respuestas similares e inferiores a la vacunación neumocócica, sin embargo, no se ha demostrado que los anti-TNF- $\alpha$ redujeran la eficacia de la vacunación neumocócica, excepto en dos estudios, donde se demostró una respuesta reducida, lo cual parece estar más relacionada a la combinación con metotrexate (MTX) independientemente de la dosis utilizada. Tampoco se ha observado ningún efecto de la actividad de la enfermedad sobre la eficacia de la vacunación antineumocócica en pacientes con AR. También en el LES, la actividad de la enfermedad no influyó sobre la eficacia de la vacunación, aunque, un ensayo abierto demostró una tendencia hacia una respuesta reducida en pacientes con lupus activo. ${ }^{37}$ Por otro lado, se ha comentado que las vacunas conjugadas proporcionan respuestas inmunológicas más potentes que las vacunas de polisacáridos, por lo tanto, los Centros para el Control y Prevención de enfermedades (CDC) de Estados Unidos, recomiendan la vacuna PCV-13 para pacientes inmunosuprimidos adultos, debido a su potencial para proporcionar una respuesta de anticuerpos específica de serotipo antineumocócica más robusta. ${ }^{38} \mathrm{La}$ inmunogenicidad y la seguridad han sido también estudiadas en pacientes con esclerosis sistémica, encontrando que la vacunación antineumocócica utilizando PCV13 o PPSV23 produjo una respuesta de anticuerpos satisfactoria en pacientes con esclerosis sistémica sin tratamiento con antirreumáticos modificadores de la enfermedad (DMARD, por sus siglas en inglés), pero con una menor respuesta en pacientes tratados con DMARDs. El tipo de vacuna antineumocócica (conjugada o polisacárida) no influyó significativamente en la respuesta de anticuerpos. ${ }^{39}$ La vacuna contra el neumococo es segura e inmunogénica en pacientes con esclerodermia, aunque el tratamiento con DMARDs puede disminuir la respuesta de anticuerpos específicos a la vacuna. La estrategia actual de vacunación usando una dosis de PCV13 seguida por una dosis de PPSV23 quizás sea una vía posible de aumentar la inmunogenicidad de la vacuna en pacientes inmunosuprimidos. ${ }^{14}$

Recomendaciones para pacientes con enfermedades reumáticas

Los pacientes con enfermedades reumatológicas inflamatorias autoinmunes son considerados inmunosuprimidos y de acuerdo a varios consensos internacionales sobre la vacunación antineumocócica:

- Es preferible vacunar con PCV13 cuando menos de 2 a 4 semanas antes del inicio de cualquier tratamiento inmunosupresor. Si se cuenta con el tiempo necesario, aplicar una dosis de PPSV23 a las 8 semanas. ${ }^{31}$

- En un paciente estable ya en tratamiento (con actividad leve o en remisión) se recomienda vacunar en cualquier momento (opinión de expertos), o bien de uno a tres meses después de finalizarlo.

- En el paciente con enfermedad activa, no se recomienda la vacunación porque no alcanzará un título protector de anticuerpos. ${ }^{40}$

- Se puede utilizar el esquema de ACIP.

- Pacientes que reciben una dosis diaria de corticoesteroides menor de $20 \mathrm{mg} / \mathrm{dí}$ a de prednisolona durante menos de 14 días o que reciben terapia con corticoesteroides alternando los días, así como pacientes que reciben MTX menos de $0.4 \mathrm{mg} / \mathrm{kg} /$ semana o azatioprina menos de $3 \mathrm{mg} / \mathrm{kg} / \mathrm{día}$, o 6 -mercaptopurina menos de $1.5 \mathrm{mg} / \mathrm{kg} /$ día, no se consideran suficientemente inmunosupresores, por lo que estos pacientes pueden recibir la vacuna igual que cualquier otro adulto. ${ }^{41,42}$

Brenol et al, en su publicación sobre las recomendaciones de vacunación para adultos con enfermedades reumáticas inflamatorias autoinmunes en América Latina en donde México participó, resumieron en el siguiente algoritmo la secuencia del uso de las dos vacunas disponibles, teniendo en cuenta que PCV13 ha mostrado una mejor respuesta inmune contra sero- 
tipos comunes a ambas vacunas y como PPV23 cubre más serotipos neumocócicos, se recomienda utilizar un esquema de vacunación secuencial. ${ }^{36}$

\section{e) Vacunación en pacientes oncológicos}

Streptococcus pneumoniae es una causa importante de morbilidad en los pacientes oncológicos. En los últimos años, la introducción masiva de la vacuna conjugada ha alterado la epidemiología de la infección neumocócica invasiva en pacientes de alto riesgo como son los pacientes oncológicos.

En esta población, la tasa de letalidad de neumonía neumocócica es mayor a la reportada en población general (5\%), por lo que algunos organismos internacionales recomiendan la vacunación contra neumococo de forma rutinaria, aunque estrictamente no se cuenta con la evidencia necesaria tomando en cuenta los diferentes subgrupos (tumores hematológicos versus no hematológicos, etapas tempranas vs etapas avanzadas, esquemas de quimioterapia que generan mayor mielosupresión versus terapia hormonal, dirigida a blancos moleculares o inmunoterapia). ${ }^{43}$

Las alteraciones en los mecanismos básicos de la inmunidad celular y la humoral, aunada a los efectos secundarios del tratamiento oncológico (particularmente quimioterapia), predisponen a los pacientes con cáncer a un mayor riesgo de desarrollar infecciones, a un curso más agresivo de la enfermedad infecciosa y a una respuesta menos efectiva a la terapia antimicrobiana.

Algunos de los factores que predisponen a la infección en pacientes oncológicos son: ${ }^{44}$

- Los tumores sólidos que obstruyen vías respiratorias bajas pueden ocasionar estasis de fluidos biológicos que favorecen las infecciones por este microorganismo.

- Los linfomas, el mieloma múltiple y las leucemias agudas y crónicas y algunos tumores sólidos se asocian con trastornos graves de la inmunidad humoral y celular, lo que predispone a este tipo de infecciones.

Durante mucho tiempo estuvo en duda la efectividad de la vacuna contra neumococo en pacientes oncológicos que reciben tratamiento con quimioterapia. Sin embargo en los últimos años, varios investigadores han reportado que un número considerable de pacientes de cáncer adultos con tratamiento citotóxico en curso, pueden montar una respuesta serológica adecuada a la vacuna antigripal y antineumocócica sin eventos adversos graves. ${ }^{45}$
En el estudio retrospectivo de Zarco-Márquez et al, llevado a cabo en el Instituto Nacional de Cancerología, México (INCan) se analizaron 103 casos de infecciones neumocócicas durante 8 años. Los casos fueron clasificados en dos categorías: invasiva y neumonía, presentándose en el 67 y 33\% respectivamente, siendo la mayoría de los pacientes hombres $(60.2 \%)$ con una media de edad de 52 años. El $43.7 \%$ de los pacientes tenían neoplasias hematológicas. En 64 muestras se realizó serotipificación encontrando que los principales serotipos identificados fueron: 3 $(n=13), 19 A(n=11), 19 F(n=5), 4(n=4)$ y $11 A(n$ = 4). El $76.5 \%$ de los aislamientos pertenecían a un serotipo contenido en la vacuna PPSV23 y $67.1 \%$ a un serotipo contenido en la vacuna PCV-13 y ningún paciente tenía un registro de haber recibido la vacuna antineumocócica. El serotipo $6 \mathrm{~A}$ tiene una alta prevalencia en pacientes con cáncer, sin embargo, en este estudio se encontró que los principales serotipos identificados fueron el 3 y el 19A (20.3 y $17.1 \%$, respectivamente). Otro hallazgo importante fue la mortalidad atribuida al proceso infeccioso, la cual fue más alta en el grupo de pacientes con enfermedad neumocócica invasiva. ${ }^{46}$

Los individuos inmunocomprometidos por cánceres hematológicos y tumores sólidos o aquellos con otros tipos de neoplasias que se encuentran recibiendo tratamientos a base de medicamentos inmunosupresores tienen un riesgo elevado de enfermedad neumocócica invasiva por lo que la vacunación con PCV13 es considerada una recomendación en este grupo de pacientes; siempre y cuando su aplicación se apegue a las normas de temporalidad recomendadas y no sea un factor que retrase el inicio de tratamiento quimioterápico. Cabe mencionar que existen tratamientos oncológicos que no generan inmunosupresión como son: antiangiogénicos, terapias de bloqueo hormonal, inmunoterapias y terapias dirigidas a blancos moleculares. ${ }^{47}$ Estos tratamientos no se encuentran estudiados en el contexto de enfermedad neumocócica invasiva en la actualidad. Se pudiera inferir que por el mecanismo de acción de ellos, no hay contraindicación aparente para la vacunación contra neumococo tomando en cuenta los beneficios clínicos observados en este tipo de pacientes al disminuir el riesgo de enfermedad neumocócica invasiva, pero la decisión de administrarla será responsabilidad del médico tratante. Por el contario, se desconoce si la coadministración de la vacuna contra neumococo y de algún tipo de inmunoterapias al actuar éstas en bloqueo de puntos de control inmune a través de anticuerpos monoclonales o bien otros productos biológicos que generen algún tipo de inmunosupresión pueden comprometer 
la efectividad y seguridad de las vacunas teniendo efecto deletéreo con una potencial implicación clínica en estos pacientes. ${ }^{48} \mathrm{De}$ ahí que las recomendaciones actuales en términos de uso concomitante de anticuerpos monoclonales y vacunas atenuadas sea esperar al menos de 3 a 6 meses de la supresión terapéutica conocida (adalimumab, certolizumab pegol, infliximab, rituximab o ustekinumab) generada por el medicamento para poder recomendar con seguridad la aplicación de la vacuna contra neumococo. ${ }^{49}$

\section{Recomendación para pacientes oncológicos}

Los pacientes oncológicos son considerados inmunosuprimidos, en quienes se puede considerar la inmunización contra el neumococo. ${ }^{14}$

La OMS recomendó la vacunación contra S. pneumoniae para diversos grupos, dentro de los cuales están incluidos los pacientes oncológicos. Esta recomendación se basa en que, si bien no hay evidencia de un beneficio absoluto de la vacunación en pacientes oncológicos, dado que aunque pudieran no alcanzar títulos similares a un paciente inmunocompetente, se plantea como una intervención cuyo riesgo-beneficio es alto, particularmente en pacientes con neoplasias hematológicas y pacientes esplenectomizados. Algunos estudios sugieren que población con tumores sólidos podrían beneficiarse, pero se requiere de mayores estudios..$^{50}$

En el manual de vacunación del 2017 del Consejo Nacional de Vacunación, una de las vacunas recomendadas en pacientes oncológicos sin esquema o con esquema de vacunación incompleto al momento del diagnóstico de cáncer, es la vacuna contra neumococo conjugada (vacuna conjugada de 13 serotipos), la cual debe administrarse en un esquema primario combinado con PPSV23 según las recomendaciones de ACIP, a partir de 3 a 6 meses posterior a las suspensión del tratamiento de quimioterapia. ${ }^{51}$

En caso de realizarse la intervención, se debe vacunar de dos a cuatro semanas antes o tres meses después de la quimioterapia y/o radioterapia. La vacunación en pacientes con recaída, estado terminal o Eastern Cooperative Oncology Group 3 (ECOG 3) quedará a consideración del médico tratante, quien deberá valorar el riesgo/beneficio. ${ }^{44}$

En el paciente con trasplante de células progenitoras hematopoyéticas se deben de administrar tres dosis de PCV13 iniciando de tres a seis meses después del trasplante. A los 12 meses después del trasplante se debe de aplicar un refuerzo de PPSV23 en los pacientes que no tienen enfermedad de injerto contra huésped. En lo que tienen enfermedad de injerto contra huésped crónica se debe de administrar una cuarta dosis de
PCV12 a los 12 meses después del trasplante (recomendación débil). ${ }^{52}$

- Todo paciente que haya concluido su tratamiento oncológico, deberá recibir la vacuna 6 meses después.

- Es importante considerar que aquellos niños menores de 2 años, que estén en convivencia cotidiana con el paciente oncológico, tengan completo su esquema de vacunación antineumocócica.

- Recordar, que la recomendación de la aplicación de la vacuna contra neumococo en pacientes con nuevos tratamientos para el cáncer como son las inmunoterapias, quedará a consideración del médico tratante puesto que es un terreno poco explorado en la actualidad.

\section{f) Vacunación en pacientes inmunosuprimidos (virus de la inmunodeficiencia humana, $\mathrm{VIH}$ )}

El Comité de Normas y Prácticas de la Sociedad de Enfermedades Infecciosas de América (IDSA) colaboró con organizaciones asociadas y con un panel de expertos en vacunación en pacientes inmunocomprometidos para dictar algunas recomendaciones sobre la vacunación en estos pacientes. Las recomendaciones para vacunar contra el neumococo en pacientes con inmunocompromiso son las siguientes: ${ }^{52}$

Deficiencias primarias (congénitas) del complemento:

- Adultos de más de 19 años con una vía clásica (C1, C2, C3, C4), vía alternativa o con deficiencia de lectina de unión a manosa (MBL) grave que no tienen PCV13 deben recibir una dosis única de PCV13 (recomendación fuerte, nivel de evidencia muy baja). Para aquellos que recibieron la vacuna PPSV23, la PCV13 debe administrarse más de año después de la última dosis de PPSV23 (recomendación débil, nivel de evidencia baja).

Pacientes adultos con inmunosupresión baja:

- Infectados por VIH con un recuento de linfocitos CD4 de más de 200 células $/ \mathrm{mm}^{3}$.

- En aquellos pacientes en los que el riesgo amerite valorar la vacunación con más de 200 linfocitos CD4, la vacuna no está contraindicada y deberán vacunarse con PCV13 al momento del diagnóstico, aunque probablemente no alcanzaran titulación adecuada de anticuerpos. Se deberá ofrecer la PPSV23 ocho semanas después de la PCV13 (cuando no la haya recibido durante los 5 años previos). 
- Se recomienda revacunar con el esquema secuencial para neumococo cuando el paciente alcance más de 200 linfocitos CD4 con tratamiento antirretroviral. ${ }^{53}$

- Pacientes que reciben una dosis diaria más baja que para la inmunosupresión alta de corticoesteroides sistémicos durante más de 14 días o que reciben terapia con corticoesteroides alternando los días.

- Pacientes que reciben MTX menos de $0.4 \mathrm{mg} / \mathrm{kg} /$ semana o azatioprina menos de $3 \mathrm{mg} / \mathrm{kg} / \mathrm{día}$, o 6-mercaptopurina menos de $1.5 \mathrm{mg} / \mathrm{kg} /$ día.

La recomendación de vacunación tanto para pacientes con inmunosupresión baja o alta, mayores de 19 años con VIH que hayan recibido PPSV23, la vacuna PCV13 debe administrarse después de un intervalo de más de 1 año después de la última dosis de PPSV23 (recomendación fuerte, nivel de evidencia bajo).

\section{Resumen: Momento oportuno de vacunación por grupo de riesgo y comorbilidad: a quién, cuándo y porqué (tablas 3 a 5).}

\section{Conclusión}

Es evidente que por el impacto de salud que ambas condiciones tienen (vacunación profiláctica versus neumonías neumocócicas en adultos, es importante identificar a los grupos en riesgo de acuerdo con las comorbilidades e individualizar a cada paciente para decidir el momento más adecuado de la vacunación en el adulto. Este documento integra el conocimiento del análisis de la información disponible al momento de la realización de estas recomendaciones, sin embargo, se mantendrá la actualización en el uso de los esquemas de vacunación y sus diferentes aplicaciones en la población en riesgo y en las áreas

\section{Tabla 3: Recomendación de vacunación por edad sin factores de riesgo (mayores de 18 años).}

\begin{tabular}{|c|c|c|}
\hline 50 a 64 años & $\begin{array}{l}\text { Se recomienda la evaluación y } \\
\text { vacunación en pacientes con } \\
\text { factores de riesgo) mayores de } 50 \\
\text { años, en función de: } \\
\text { - Aumento de la tasa de incidencia } \\
\text { de NAC a partir de los } 50 \text { años }^{8} \\
\text { Cinco veces más comparada con } \\
\text { el grupo de } 5 \text { a } 49 \text { años } \\
\text { - Mayor frecuencia de comorbilida- } \\
\text { des a partir de los } 40 \text { años en la } \\
\text { población mexicana }{ }^{54,55} \\
\text { - PCV13 es segura y bien tolerada } \\
\text { en pacientes mayores de } 50 \text { años } \\
\text { demostrando una buena respuesta } \\
\text { inmunológica en este grupo } 56,57\end{array}$ & $\begin{array}{l}\text { Desde el primer contacto con el pa- } \\
\text { ciente se puede evaluar su riesgo. } \\
\text { Si el paciente está hospitalizado, se } \\
\text { puede vacunar al egreso hospitalario, } \\
\text { incluyendo aquellos casos que tuvie- } \\
\text { ron neumonía por otras causas. }\end{array}$ \\
\hline Más de 65 años & $\begin{array}{l}\text { A la edad de } 65 \text { años o más, } \\
\text { administrar una dosis de la vacuna } \\
\text { PCV13 para aquellos adultos que } \\
\text { no han recibido ninguna vacuna } \\
\text { o para aquellos en quienes se des- } \\
\text { conoce su historial de vacunación }\end{array}$ & $\begin{array}{l}\text { Al cumplir } 65 \text { años, tan pronto como } \\
\text { sea posible }\end{array}$ \\
\hline
\end{tabular}




\section{Tabla 4: Recomendación de vacunación por condición de salud (comorbilidades)/por grupo en riesgo.}

Condición de salud

Inmunodeficiencia (excepto $\mathrm{VIH}$ )

Enfermedades del corazón (excepto hipertensión), alcoholismo, diabetes mellitus tipo 1 y 2 y enfermedad hepática crónica

Enfermedades respiratorias crónicas

Pacientes con enfermedad inflamatoria intestinal, enfermedad de Crohn, colitis ulcerosa

Tabaquismo

Trisomía 21

\section{Recomendación vacunación PCV13 y justificación}

Vacunar con PCV13 (una dosis) seguida de una dosis de PPSV23 al menos 8 semanas después

Al cumplir 65 años

Aunque la recomendación es vacunar a los 65 años, se puede evaluar la condición del paciente y vacunar a los 50 años, por ser comorbilidades que incrementan el riesgo de neumonía

Pacientes con asma, enfermedad obstructiva crónica, (EPOC), fibrosis pulmonar, con bronquiectasias que han requerido hospitalización, debido a que las exacerbaciones infecciosas deterioran la función pulmonar y aumentan la tasa de mortalidad

A los 65 años, dependiendo de otras comorbilidades se deja abierta la posibilidad de vacunar antes de los 65 años con PCV13

Todo paciente mayor o igual a 50 años y aquellos que reciban algún anticuerpo monoclonal o esteroides deben ser vacunados independientemente de la edad, de preferencia previo al inicio del tratamiento inmunosupresor

A los 65 años. En pacientes adultos mayores de 19 años evaluar la condición del paciente y considerar, en su caso, la vacunación

A los 65 años, dependiendo de otras comorbilidades se deja abierta la posibilidad de vacunar antes de los 65 años con PCV13
Tiempo

Al diagnóstico y en cuanto cumplan 65, aplicar PCV13

En pacientes con infarto al miocardio con colocación de stents podría ser en el hospital, en los que requieran cirugía a los 30 días del posoperatorio

En pacientes con enfermedad valvular, vacunar tan pronto sea posible, $y$ de preferencia antes de un procedimiento quirúrgico

Evaluar al paciente desde el primer contacto (al momento del diagnóstico)

Si el paciente está hospitalizado vacunar al egreso hospitalario, incluyendo los casos de neumonía de cualquier etiología 


\begin{tabular}{|c|c|c|}
\hline $\begin{array}{l}\text { Pacientes con } \\
\text { inmunocompromiso }\end{array}$ & Recomendación vacunación PCV13 y justificación & Tiempo \\
\hline $\begin{array}{l}\text { Inmunodeficiencia } \\
(\mathrm{VIH})\end{array}$ & $\begin{array}{l}\text { Se recomienda la vacunación tanto para pacientes con } \\
\text { inmunosupresión baja o alta, mayores de } 19 \text { años con } \\
\text { VIH que hayan recibido PPSV23, con la vacuna PCV13, } \\
\text { la cual debe administrarse después de un intervalo de } \\
\text { más de un año después de la última dosis de PPSV23 } \\
\text { (recomendación fuerte, nivel de evidencia bajo) }\end{array}$ & Al momento del diagnóstico \\
\hline $\begin{array}{l}\text { VIH: CD4 menor de } \\
200\end{array}$ & $\begin{array}{l}\text { Cuando se incrementen los CD4, vacunar con PCV13 } \\
\text { (una dosis) seguida de una dosis de PPSV23 al menos } \\
8 \text { semanas después }\end{array}$ & $\begin{array}{l}\text { Esperar a que se incrementen } \\
\text { los CD4 (mayor de 200) }\end{array}$ \\
\hline $\begin{array}{l}\text { VIH: CD4 mayor de } \\
200\end{array}$ & $\begin{array}{l}\text { En aquellos pacientes con más de } 200 \text { linfocitos CD4 } \\
\text { en los que el riesgo amerite valorar la vacunación y } \\
\text { la vacuna no está contraindicada, deberán vacunar- } \\
\text { se con PCV13 al momento del diagnóstico, aunque } \\
\text { probablemente no alcanzaran titulación adecuada de } \\
\text { anticuerpos. Se deberá aplicar la PPSV23 ocho sema- } \\
\text { nas después de la PCV13 (cuando no la hayan recibido } \\
\text { durante los cinco años previos) }\end{array}$ & $\begin{array}{l}\text { Vacunar al momento del } \\
\text { diagnóstico y cuando no haya } \\
\text { infecciones activas y el paciente } \\
\text { tenga menos de } 50 \text { copias } / \mathrm{ml}\end{array}$ \\
\hline $\begin{array}{l}\text { Otras } \\
\text { inmunodeficiencias }\end{array}$ & $\begin{array}{l}\text { Se recomienda la vacunación tanto para pacientes con } \\
\text { inmunosupresión baja o alta, mayores de } 19 \text { años con } \\
\text { VIH que hayan recibido PPSV23, con la vacuna PCV13, } \\
\text { la cual debe administrarse después de un intervalo de } \\
\text { más de } 1 \text { año después de la última dosis de PPSV23 } \\
\text { (recomendación fuerte, nivel de evidencia bajo) }\end{array}$ & Al momento del diagnóstico \\
\hline $\begin{array}{l}\text { Esplenectomía o } \\
\text { asplenia funcional }\end{array}$ & $\begin{array}{l}\text { Vacunar con PCV13 (una dosis) seguida de una dosis } \\
\text { de PPSV23 al menos ocho semanas después y una se- } \\
\text { gunda dosis de PPSV23 al menos cinco años después }\end{array}$ & $\begin{array}{l}\text { Antes de la esplenectomía si es } \\
\text { posible o } 30 \text { días después de la } \\
\text { misma. En bazo deficiente tan } \\
\text { pronto sea posible y sin infeccio- } \\
\text { nes activas }\end{array}$ \\
\hline $\begin{array}{l}\text { Pacientes con } \\
\text { implante coclear }\end{array}$ & $\begin{array}{l}\text { Se recomienda aplicar la vacuna PCV13 independiente- } \\
\text { mente del grupo de edad. } \\
\text { En los pacientes pediátricos y adultos jóvenes, es im- } \\
\text { perativo revisar el antecedente vacunal versus neumo- } \\
\text { coco y verificar su adecuada cobertura. Para el adulto, } \\
\text { vacunar preferentemente antes de la cirugía }\end{array}$ & Tan pronto como sea posible \\
\hline $\begin{array}{l}\text { Insuficiencia renal } \\
\text { crónica y síndrome } \\
\text { nefrótico }\end{array}$ & $\begin{array}{l}\text { Vacunar con PCV13 (una dosis) seguida de una dosis } \\
\text { de PPSV23 al menos ocho semanas después y una se- } \\
\text { gunda dosis de PPSV23 al menos cinco años después. } \\
\text { Dado el número y gravedad de las infecciones, debido } \\
\text { al edema periférico, pérdida de factores de la vía alterna } \\
\text { del complemento y las alteraciones en la función leuco- } \\
\text { citaria y esplénica }\end{array}$ & Tan pronto como sea posible \\
\hline
\end{tabular}




\begin{tabular}{|c|c|c|}
\hline $\begin{array}{l}\text { Pacientes con } \\
\text { inmunocompromiso }\end{array}$ & Recomendación vacunación PCV13 y justificación & Tiempo \\
\hline Pacientes oncológicos & $\begin{array}{l}\text { En el manual de vacunación del } 2017 \text { del Consejo } \\
\text { Nacional de Vacunación, una de las vacunas recomen- } \\
\text { dadas en pacientes oncológicos sin esquema o con } \\
\text { esquema de vacunación incompleto al momento del } \\
\text { diagnóstico de cáncer, es la vacuna contra neumococo } \\
\text { conjugada (vacuna conjugada de } 13 \text { serotipos), la } \\
\text { cual debe administrarse en un esquema primario combi- } \\
\text { nado con PPSV23 según las recomendaciones de ACIP } \\
\text { a partir de } 3 \text { a } 6 \text { meses posterior a las suspensión del } \\
\text { tratamiento de quimioterapia }\end{array}$ & $\begin{array}{l}\text { Idealmente debe administrarse } \\
\text { antes de la quimioterapia. Si no } \\
\text { ha sido así, se recomienda espe- } \\
\text { rar que el paciente complete la } \\
\text { quimioterapia mieloablativa para } \\
\text { efectuar la vacunación }\end{array}$ \\
\hline $\begin{array}{l}\text { Pacientes en trata- } \\
\text { miento con inmunosu- } \\
\text { presores. Enfermeda- } \\
\text { des reumáticas como } \\
\text { artritis reumatoide, } \\
\text { lupus eritematoso sis- } \\
\text { témico, entre otros }\end{array}$ & $\begin{array}{l}\text { Pacientes que reciben una dosis diaria de corticoes- } \\
\text { teroides menor de } 20 \mathrm{mg} / \mathrm{día} \text { de prednisolona durante } \\
\text { menos de } 14 \text { días o que reciben terapia con corticoes- } \\
\text { teroides alternando los días, así como pacientes que } \\
\text { reciben MTX menos de } 0.4 \mathrm{mg} / \mathrm{kg} / \mathrm{semana} \text { o azatioprina } \\
\text { menos de } 3 \mathrm{mg} / \mathrm{kg} / \mathrm{día} \text {, o } 6 \text {-mercaptopurina menos de } \\
1.5 \mathrm{mg} / \mathrm{kg} / \mathrm{día} \text {, no se consideran suficientemente inmu- } \\
\text { nosupresores, por lo que estos pacientes pueden recibir } \\
\text { la vacuna igual que cualquier otro adulto } \\
\text { - Es preferible vacunar cuando menos de dos a cuatro } \\
\text { semanas antes del inicio de cualquier tratamiento } \\
\text { inmunosupresor } \\
\text { - En un paciente estable en tratamiento (con actividad } \\
\text { leve o en remisión) se recomienda vacunar en cual- } \\
\text { quier momento (opinión de expertos), o bien de uno a } \\
\text { tres meses después de finalizarlo } \\
\text { - En el paciente con enfermedad activa, no se reco- } \\
\text { mienda la vacunación porque no alcanzará un título } \\
\text { protector de anticuerpos (EULAR, 2011) } \\
\text { Vacunar con PCV13 (una dosis) seguida de una dosis } \\
\text { de PPSV23 al menos ocho semanas después y una se- } \\
\text { gunda dosis de PPSV23 al menos cinco años después }\end{array}$ & \\
\hline $\begin{array}{l}\text { Pacientes } \\
\text { trasplantados }\end{array}$ & $\begin{array}{l}\text { Vacunar con PCV13 (una dosis) seguida de una dosis } \\
\text { de PPSV23 al menos ocho semanas después y una se- } \\
\text { gunda dosis de PPSV23 al menos cinco años después }\end{array}$ & Antes de la cirugía \\
\hline
\end{tabular}

Notas:

- En pacientes inmunocomprometidos, la vacuna PCV13 debe ser la primera que reciban y posteriormente se podría aplicar una dosis de PPSV23 a las ocho semanas. ${ }^{52}$

- En quienes ya recibieron una dosis de PPSV23, se puede aplicar la vacuna PCV13 (una dosis) al año de la aplicación. ${ }^{52}$

- En pacientes de 18 a 49 años se recomienda hacer una valoración del riesgo de NAC y del estado general para buscar intencionadamente si cuentan con factores de riesgo como tabaquismo activo o pasivo, exposición prolongada a gases tóxicos y antecedentes de alergias para evaluar la elegibilidad a criterio del médico para recibir la vacuna PCV13.

- Se recomienda la vacunación con PCV13 en aquellos casos que tuvieron neumonía por otras causas.

- Revacunación.

- Quien haya recibido PPSV23 anteriormente deberá recibir una dosis de PCV13 si tiene indicación y no revacunar con PPSV23. ${ }^{52}$ 
de oportunidad detectadas. La información contenida en este documento nos invita a la implementación en la práctica clínica rutinaria, por lo que estas recomendaciones son de utilidad como apoyo en la toma de decisiones de los médicos generales y especialistas para la implementación de esta medida de prevención.

\section{Declaración de conflicto de intereses}

Las autoras principales y los coautores declaramos ningún conflicto de intereses, dado que ninguno de los que participamos en la elaboración del documento recibimos ningún tipo de honorarios, emolumentos o pagos en directo o en especie de algún ente específico fuera de nuestra adscripción. Sólo se llevó a cabo una reunión presencial para discutir los puntos del documento, la cual fue patrocinada por Pfizer.

\section{REFERENCIAS}

1. Prevención, diagnóstico y tratamiento de la neumonía adquirida en la comunidad. Guía de Evidencias y Recomendaciones. Guía de Práctica Clínica. México, CENETEC; 2017. Disponible en: http://www.cenetec.salud. gob.mx/contenidos/gpc/catalogoMaestroGPC.html\#

2. Dang TT, Eurich DT, Weir DL, Marrie TJ, Majumdar SR. Rates and risk factors for recurrent pneumonia in patients hospitalized with community- acquired pneumonia: population-based prospective cohort study with 5 years of follow-up. Clin Infectious Dis 2014;59(1):74-80.

3. Rivero-Calle I, Pardo-Seco J, Aldaz P, Vargas DA, Mascaros $\mathrm{E}$, Redondo $\mathrm{E}$, et al. Incidence and risk factor prevalence of community-acquired pneumonia in adults in primary care in Spain (NEUMO-ES-RISK project). BMC Infectious Dis 2016;16:645.

4. Chalmers JD, Campling J, Dicker A, Woodhead M, Madhava H. A systematic review of the burden of vaccine preventable pneumococcal disease in UK adults. BMC Pulmonary Med 2016;16:77.

5. Mandell LA, Wunderink RG. Neumonía (capítulo 153). En: Kasper DL, Hauser SL, Jameson JL, et al. editores. Harrison Principios de Medicina Interna. Vol 2. 19a ed. México: McGraw-Hill; 2015. pp. 803-806.

6. Escobar-Rojas A, Castillo-Pedroza J, Cruz-Hervert P, Báez-Saldaña R. Tendencia de morbilidad y mortalidad por neumonía en adultos mexicanos (1984-2010). Neumol Cir Torax 2015;74(1):4-12.

7. Tasa de morbilidad de los principales casos nuevos de enfermedades, 2000 a 2013. Consultado en: http://www3.inegi.org.mx/sistemas/sisept/default. aspx? $\mathrm{t}=\mathrm{msal06} \& \mathrm{~s}=\mathrm{est} \& \mathrm{c}=22462$

8. Báez-Saldaña R, Gómez-Zamora C, López-Elizondo C, Molina-Corona H, Santillán-Martínez A, Sánchez-Hernández J, et al. Neumonía adquirida en la comunidad. Revisión y actualización con una perspectiva orientada a la calidad de la atención médica. Neumol Cir Torax 2013;72(1):6-43.
9. Trejo-Valdivia B, Mendoza-Alvarado LR, Palma-Coca O, Hernández-Ávila M, Téllez-Rojo Solís MM, et al. Encuesta Nacional de Cobertura de Vacunación (influenza, neumococo y tétanos) en Adultos Mayores de 60 años en México. Salud Publica Mex 2012;54:39-46.

10. Julio V, Vacarezza M, Álvarez C, Sosa A. Niveles de atención, de prevención y atención primaria de la salud. Arch Med Interna 2011;33(1):11-14.

11. Evolución de las vacunas contra Streptococcus pneumoniae. Consultado en: https://www. historyofvaccines.org/es/contenido/articulos/ enfermedad-neumoc\%C3\%B3cica

12. Prevention of Pneumococcal Disease. Recommendations of the advisory committee on immunization practices (ACIP). MMWR 1997;46:1-24.

13. Introduction of Pneumococcal Vaccine PCV10. A handbook for district and health facility staff. WHO 2013. Consultado en: https://apps.who.int/iris/ bitstream/handle/10665/90378/WHO_IVB 13.09_eng. pdf; jsessionid = C7C92B23CA6AF4251Ā67DC1B7C̄069F $\mathrm{DE}$ ? sequence $=1$

14. González-Romo F, Picazo JJ, García-Rojas A, LabradorHorrillo M, Barrios V, Magro MC, et al. Consenso sobre la vacunación anti-neumocócica en el adulto por riesgo de edad y patología de base. Actualización 2017. Rev Esp Quimioter 2017;30(2):142-168.

15. Definición conjugada y polisacárida. Consultado en: https://www.cdc.gov/pneumococcal/vaccination-sp. html

16. Información para prescribir amplia Prevenar ${ }^{\circledR 13 \mathrm{~V}}$.

17. Pletz MW, Maus U, Krug N, WelteT, Lode H. Pneumococcal vaccines: mechanism of action, impact on epidemiology and adaption of the species. Int J Antimicrobial Agents. 2008;32:199-206.

18. Información para prescribir Pneumo23. Consultada en: http://www.medicamentosplm.com/Home/productos/ pneumo_23_solucion_inyectable/161/101/9308/162

19. 2018 Recommended immunizations for adults by age and by Health condition CDC. Consultada en: https:// www.cdc.gov/vaccines/schedules/downloads/adult/ adult-schedule-easy-read.pdf

20. Suaya JA, Jiang Q, Scott DA, Gruber WC, Webber C, Schmoele-Thoma B, et al. Post hoc analysis of the efficacy of the 13-valent pneumococcal conjugate vaccine against vaccine-type community-acquired pneumonia in at-risk older adults. Vaccine 2018;36:1477-1483.

21. Tanriöver MD, Akar S, Türkcapar N, Karadag O, Ertenli I, Kiraz S. Vaccination recommendations for adult patients with rheumatic diseases. Eur J Rheumatol 2016;3:29-35.

22. Gutiérrez-Robledo LM, Caro-López E, Guerrero-Almeida ML, Dehesa-Violante M, Rodríguez-Noriega E, GarcíaLara JM, et al. 10 Consenso Mexicano de Vacunación en el Adulto. Gac Med Mex 2017;153:5-70.

23. Steel HC, Cockeran R, Anderson R, Feldman C. Overview of community-acquired pneumonia and the role of inflammatory mechanisms in the immunopathogenesis of severe pneumococcal disease. Mediators of Inflammation 2013; http://dx.doi. org/10.1155/2013/490346 
24. Bonten MJM, Huijts SM, Bolkenbaas M, Webber C, Patterson S, Gault S, et al. Polysaccharide conjugate vaccine against pneumococcal pneumonia in adults. $\mathrm{N}$ Engl J Med 2015;372:1114-1125.

25. Intervals Between PCV13 and PPSV23 Vaccines: Recommendations of the Advisory Committee on Immunization Practices (ACIP). Consultado en: https:// www.cdc.gov/mmwr/preview/mmwrhtml/mm6434a4. htm?s cid =mm6434a4 w

26. Declaratoria emergenciā epidemiológica por diabetes mellitus. Consultada en: https://www.gob.mx/salud/ prensa/emite-la-secretaria-de-salud-emergenciaepidemiologica-por-diabetes-mellitus-y-obesidad

27. Kesavadeb J, Misra A, Kumar-Das A, Saboo B, Basu D, Thomas $M$, et al. Suggested use of vaccines in diabetes. Indian J Endocrinol Metab 2012;16(6):886-893.

28. Klekotka RB, Mizgala E, Krol W. The etiology of lower respiratory tract infections in people with diabetes. Pneumonol Alergol Pol 2015;83:401-408.

29. Van Deursen AMM, van Houten MA, Webber C, Patton M, Scott DA, Patterson S, et al. Immunogenicity of the 13-valent pneumococcal conjugate vaccine in older adults with and without comorbidities in the community-adquired pneumonia immunization trial in adults (CAPiTA). Clin Infectious Dis 2017;65(5):787795.

30. 2017 ADA Guidelines: Comorbidities and Diabetes: Immunization. Consultado en: https://www. gertitashkomd.com/blog/2017/5/12/2017-adaguidelines-comorbidities-and-diabetes

31. Recommended Immunization Schedule for Adults Aged 19 years or Older, United States, 2018. Consultado en: https://www.cdc.gov/vaccines/schedules/hcp/imz/adultconditions.html

32. Martins WA, Domingues-Ribeiro M, Brandáo de Oliveira L, da Silva-Nogueira de Barros L, da Silva Moreira Jorge $\mathrm{C}$, et al. Vacunación contra Influenza y Neumococo en la Insuficiencia Cardíaca - Una recomendación poco aplicada. Arq Bras Cardiol 2011;96(3):240-245.

33. Bornheimer R, Shea KM, Sato R, Weycker D, Pelton SI. Risk of exacerbation following pneumonia in adults with heart failure or chronic obstructive pulmonary disease. PLoS ONE 2017;12(10):e0184877.

34. Corrales-Medina VF, Alvarez KN, Weissfeld LA, Angus DC, Chirinos JA, Chang CCH, et al. Association between hospitalization for pneunomia and subsequent risk of cardiovascular disease. JAMA 2015;313(3):264-274.

35. Elkayam O, Paran D, Caspi D, Litinsky I, Yaron M, Charboneau D, et al. Immunogenicity and safety of pneumococcal vaccination in patients with rheumatoid arthritis or systemic lupus erythematosus. Clin Infectious Dis 2002;34:147-153.

36. Brenol CV, Azevedo VF, Bonvehi PE, Coral-Alvarado PX, Granados J, Muñoz-Louis R, et al. Vaccination recommendations for adults with autoimmune inflammatory rheumatic diseases in Latin America. J Clin Rheumatol. 2018;24(3):138-147.

37. Van Assen S, Elkayam O, Agmon-Levin N, Cervera R, Doran MF, Dougados $\mathrm{M}$, et al. Vaccination in adult patients with auto-immune inflammatory rheumatic diseases: A systematic literature review for the European League Against Rheumatism evidence-based recommendations for vaccination in adult patients with auto-immune inflammatory rheumatic diseases. Autoimmunity Rev 2011;10:341-352.

38. Meroni PL, Zavaglia D, Girmenia C. Vaccinations in adults with rheumatoid arthritis in an era of new diseasemodifying anti-rheumatic drugs. Clin Exp Rheumatol 2018;36:317-328.

39. Hesselstrand R, Nagel J, Saxne T, Geborek P, Skattum L, Kapetanovic MC. Immunogenicity and safety of pneumococcal vaccination in patients with systemic sclerosis. Rheumatol 2018;57(4):625-630.

40. Van Assen S, Agmon-Levin N, Elkayam O, Cervera R, Doran MF, Dougados M, et al. EULAR Recommendations for Vaccination in adult patients with autoimmune inflammatory rheumatic diseases. Ann Rheum Dis 2011;70:414-422.

41. Kumar S, Rath P, Malaviya AN. A practical guide to adult vaccination for patients with autoimmune inflammatory rheumatic diseases in India. Indian J Rheumatol 2017;12:160-168.

42. Westra J, Rondaan C, van Assen S, Bijl M. Vaccination of patients with autoimmune inflammatory rheumatic diseases. Nat Rev Rheumatol 2015;11(3):135-145.

43. Wong A, Marrie TJ, Garg S, Kellner JD, Tyrrell GJ, et al. Increased risk of invasive pneumococcal disease in haematological and solid-organ malignancies. Epidemiol Infect 2010;138:1804-1810.

44. Guía de práctica clínica basada en la evidencia sobre la eficacia de la vacunación contra Streptococcus pneumoniae y virus influenza en pacientes oncológicos. 2007. Consultada en: http://www.cancer.gov.co/files/libros/archivos/ f7ec662fccc31d9f9446a9c62a159324_Guia\%20N4\%20 \%20pacientes\%20vacunas\%20con\%20cancer.pdf

45. Berglund A, Willen L, Grödeberg L, Skattum L, Hagberg $\mathrm{H}$, Pauksens $\mathrm{K}$. The response to vaccination against influenza $A$ (H1N1) 2009, seasonal influenza and Streptococcus pneumonia in adult outpatients with ongoing treatment for cancer with and without rituximab. Acta Oncologica 2014;53:1210-1220.

46. Zarco-Márquez $S$, Volkow-Fernández $P$, VelázquezAcosta C, Echániz-Áviles G, Carnalla-Barajas MN, Soto-Noguerón A, et al. Invasive and complicated pneumococcal infection in patients with cancer. Rev Inves Clin 2016;68:221-228.

47. Toleman MS, Herbert K, McCarthy N, Church DN. Vaccination of chemotherapy patients-effect of guideline implementation. Support Care Cancer 2016;24(5):2317-2321.

48. Rodrigo C. Intervalos de administración de vacunas entre sí y entre vacunas y otros productos inmunobiológicos. Intercambio de preparados vacunales. En: Arístegui J (Ed.). Vacunaciones en el niño. De la teoría a la práctica. Bilbao: Ciclo Editorial; 2004. pp. 93-97.

49. Ullrich D, Ullrich K, Mussler S, Thum-Oltmer S. Vaccination during concurrent subcutaneous immunotherapy: safety of simultaneous application. Eur Ann Allergy Immunol 2015;47:10-14. 
50. Chicaíza-Becerra LA, García-Molina M, Ballesteros M, Gamboa O, Díaz J, Vega R, et al. Impacto económico de la vacuna contra el neumococo en pacientes oncológicos. Rev Salud Pública 2007;9(3):342-352.

51. Manual de Vacunación CONAVA 2017. Consultado en: http://bit.ly/2n1vF8S

52. Rubin LG, Levin MJ, Ljungman P, Davies EG, Avery R, Tomblyn M, et al. 2013 IDSA Clinical Practice Guideline for Vaccination of the Immunocompromised Host. Clin Infectious Dis 2014;58(3):e44-100.

53. Guidelines for the Prevention and Treatment of Opportunistic Infections in HIV-Infected Adults and Adolescents. https:// aidsinfo.nih.gov/guidelines/html/4/adult-and-adolescentopportunistic-infection/365/figure--immunization https:// aidsinfo.nih.gov/guidelines/html/4/adult-and-adolescentopportunistic-infection/365/figure--immunization

54. Informe sobre la salud de los mexicanos 2015. Consultado en: https://www.gob.mx/cms/uploads/
attachment/file/64176/INFORME_LA_SALUD_DE_LOS_ MEXICANOS_2015_S.pdf

55. Informe sob̄re la salud de los mexicanos 2016. Consultado en: https://www.gob.mx/salud/documentos/ informe-sobre-la-salud-de-los-mexicanos-2016116713 ?state $=$ published

56. Tinoco JC, Juergens C, Ruiz-Palacios GM, VázquezNarváez J, Enkerlin-Pauwells HL, Sundaraiyer V, et al. Open-label trial of immunogenicity and safety of a 13-valent pneumococcal conjugate vaccine in adults 50 years of age in Mexico. Clin Vaccine Immunol 2015;22(2):185-192.

57. Solanki BB, Juergens C, Chopada MB, Supe $P$, Sundariyer V, Le Dren-Narayanin N, et al. Safety and immunogenicity of a 13-valent pneumococcal conjugate vaccine in adults 50 to 65 years of age in India: An open-label trial. Human Vaccines \& Immunotherapeutics 2017;13(9):2065-2071. 